\title{
On the Extraordinary Intensification of Hurricane Patricia (2015). Part I: Numerical Experiments
}

\author{
NANNAN QIN \\ Key Laboratory of Meteorological Disaster, Ministry of Education, Nanjing University of Information \\ Science and Technology, Nanjing, China, and Department of Atmospheric and Oceanic Science, University of \\ Maryland, College Park, College Park, Maryland \\ DA-LIN ZHANG \\ Department of Atmospheric and Oceanic Science, University of Maryland, College Park, College Park, Maryland
}

(Manuscript received 19 March 2018, in final form 14 August 2018)

\begin{abstract}
Hurricane Patricia (2015) broke records in both peak intensity and rapid intensification (RI) rate over the eastern Pacific basin. All of the then-operational models predicted less than half of its extraordinary intensity and RI rate, leaving a challenge for numerical modeling studies. In this study, a successful 42-h simulation of Patricia is obtained using a quintuply nested-grid version of the Weather Research and Forecast (WRF) Model with the finest grid size of $333 \mathrm{~m}$. Results show that the WRF Model, initialized with the Global Forecast System Final Analysis data only, could reproduce the track, peak intensity, and many inner-core features, as verified against various observations. In particular, its simulated maximum surface wind of $92 \mathrm{~m} \mathrm{~s}^{-1}$ is close to the observed $95 \mathrm{~m} \mathrm{~s}^{-1}$, capturing the unprecedented RI rate of $54 \mathrm{~m} \mathrm{~s}^{-1}(24 \mathrm{~h})^{-1}$. In addition, the model reproduces an intense warm-cored eye, a small-sized eyewall with a radius of maximum wind of less than $10 \mathrm{~km}$, and the distribution of narrow spiral rainbands. A series of sensitivity simulations is performed to help understand which model configurations are essential to reproducing the extraordinary intensity of the storm. Results reveal that Patricia's extraordinary development and its many inner-core structures could be reasonably well simulated if ultrahigh horizontal resolution, appropriate model physics, and realistic initial vortex intensity are incorporated. It is concluded that the large-scale conditions (e.g., warm sea surface temperature, weak vertical wind shear, and the moist intertropical convergence zone) and convective organization play important roles in determining the predictability of Patricia's extraordinary $\mathrm{RI}$ and peak intensity.
\end{abstract}

\section{Introduction}

Hurricane Patricia (2015) was an extraordinary rapidly intensifying storm that broke records in terms of both its peak intensity and the intensification rate over the eastern North Pacific and the North Atlantic basins, with a minimum central sea level pressure $P_{\mathrm{MIN}}$ of $872 \mathrm{hPa}$ and a maximum surface wind $V_{\text {MAX }}$ of over $95 \mathrm{~m} \mathrm{~s}^{-1}$, as well as an extraordinary rapid intensification (RI) rate of $54 \mathrm{~m} \mathrm{~s}^{-1}$ and $97 \mathrm{hPa} \mathrm{day}^{-1}$ (Rogers et al. 2017), where RI is defined herein as an intensification rate of greater than $15.4 \mathrm{~m} \mathrm{~s}^{-1}$ day $^{-1}$ in $V_{\text {MAX }}$, following Kaplan and DeMaria (2003). In hindsight, Patricia's strong intensity was expected, but not the degree to which it would intensify, and it did so rapidly (Kimberlain et al. 2016), given its development

\footnotetext{
Corresponding author: Dr. Da-Lin Zhang, dalin@umd.edu
}

in a very favorable environment with high sea surface temperature (SST), high ocean heat content, weak vertical wind shear (VWS), and ample low-tropospheric moisture (Gray 1968; Holliday and Thompson 1979; Emanuel 1986; Holland 1997). However, all of the then-operational hurricane models, initialized at any time, failed severely in predicting Patricia's extreme intensity and RI rate, although its genesis and track could be well predicted 3-4 days in advance (Kimberlain et al. 2016; Rogers et al. 2017). The highest $V_{\text {MAX }}$ ever predicted by any operational model initialized $36 \mathrm{~h}$ earlier was less than half of the observed peak intensity, implying that the favorable environmental conditions mentioned above are insufficient prerequisites for predicting the extreme RI and intensity of Patricia by hurricane models.

Naturally, one may ask the following two questions: Why was Patricia's intensity underpredicted by less than half, 
given the favorable environmental conditions that should be reasonably well represented by today's hurricane models? What physical or dynamical components were essential in reproducing such an extreme RI of the storm? Thus, we are motivated to address the two above questions in this study by conducting a series of cloudpermitting simulations with the Weather Research and Forecasting (WRF) Model.

It should be pointed out that the abovementioned poor predictability of the RI and extraordinary intensity of Patricia has been of typical concern for many tropical cyclones (TCs) (Tallapragada and Kieu 2014), despite significant improvements in hurricane models and rapid progress in predicting hurricane tracks during the recent decades (Rappaport et al. 2009). In fact, it is well known that our ability to predict hurricane intensity and intensity changes, especially for rapidly intensifying hurricanes, has been severely hampered partly by the lack of high-resolution observations to improve the quality of the model initial conditions, especially over vast tropical oceans where few upper-air observations are available, and partly by deficiencies in the current numerical weather prediction (NWP) models, including the model horizontal and vertical resolutions used. Furthermore, the poor predictability of hurricane intensity can be attributed to our limited understanding of multiscale interactive processes, especially those occurring in the inner-core regions (Marks et al. 1998; Hendricks et al. 2010; Susca-Lopata et al. 2015). Earlier theoretical studies have shown that latent heat release in intensifying TCs is more efficient when it occurs within the eyewall, with strong inertial stability, than when it occurs outside the eyewall (Schubert and Hack 1982; Willoughby et al. 1982). Previous studies indicate the importance of convective bursts, characterized by intense updrafts in the eyewall, in facilitating the RI when these bursts occur over high-SST regions (Steranka et al. 1986; Rodgers et al. 1998; Heymsfield et al. 2001; Guimond et al. 2010; Chen and Zhang 2013; Rogers et al. 2013). The convective bursts in the eyewall appear to account for the development of an intense upper-level warm core or double warm cores during the RI (Zhang and Chen 2012; Wang and Wang 2014; Kieu et al. 2016).

Recently, some attention has been paid to the relationship between TC intensity and size changes (Carrasco et al. 2014; Xu and Wang 2015; Qin et al. 2016). TC intensification is often accompanied by the contraction of the radius of maximum wind (RMW) and the inward advection of the absolute angular momentum (Schubert and Hack 1982; Willoughby 1990; Zhang et al. 2001). The inward angular momentum transport is more evident in the planetary boundary layer (PBL), where radial inflows are peaked. In addition, $\mathrm{Xu}$ and Wang (2015) found that TC intensification rate is negatively and positively correlated with the RMW and storm intensity (i.e., $V_{\mathrm{MAX}}$ ), respectively. The highest RI tends to occur when the RMW is less than $40 \mathrm{~km}$ with $V_{\text {MAX }}$ of about $40 \mathrm{~m} \mathrm{~s}^{-1}$.

Although little progress has been made in operationally predicting the RI of TCs, cloud-permitting simulations of some rapidly intensifying TCs, such as Hurricanes Andrew (1992), Katrina (2005), Wilma (2005), and Typhoon Megi (2010), have been successfully obtained (e.g., Liu et al. 1999; Houze et al. 2007; Chen et al. 2011; Wang and Wang 2014). These studies have provided some important insights into the inner-core structures of TCs and their relation to the RI of TCs. In particular, it is now possible to reproduce reasonably well the TCs' inner-core features, such as the small-sized eye and RMW, asymmetric eyewall structures, narrow spiral rainbands, and eyewall replacement cycles (Zhu et al. 2004; Houze et al. 2007; Chen et al. 2011). Many of these features are not well captured by today's operational NWP models, as they have not reached the skill level of statistical intensity models in many cases (Rappaport et al. 2009; Kaplan et al. 2015). These inner-core structures also appear to be closely related to intensity changes and the peak intensity of TCs. In addition, some important interactive processes leading to the RI of hurricanes are poorly represented by current NWP models, such as air-sea interaction, innercore dynamical and thermodynamic processes, and cloud microphysics (Emanuel 1986; Zhu and Zhang 2006; Chen and Zhang 2013; Miller et al. 2015).

Therefore, the objectives of this study are to (i) determine to what extent a cloud-permitting version of the Weather Research and Forecasting (WRF) Model can reproduce the extreme RI and peak intensity of Patricia; (ii) demonstrate how numerous inner-core structures, including its small storm size, and multiple spiral rainbands, could be reproduced, as verified against various observations, by the WRF Model initialized by the National Centers for Environmental Prediction (NCEP) Global Forecast System (GFS) Final Analysis (FNL) dataset without assimilating any extra data; and (iii) examine what parameters are important in reproducing Patricia's extreme RI and intensity through a series of sensitivity simulations. In particular, Hurricane Patricia (2015) developed during the field campaign of the Office of Naval Research Tropical Cyclone Intensity (TCI; Doyle et al. 2017) and the National Oceanic and Atmospheric Administration (NOAA) P-3 missions (Rogers et al. 2017), which provided ample three-dimensional high-resolution observations across the storm for validating the model-simulated inner-core structures of the storm. It should be mentioned that Fox and Judt (2018) have obtained a 60-h simulation of Patricia, initialized 
at 0000 UTC 22 October, using the WRF Model with the inclusion of dissipative heating (Zhang and Altshuler 1999 ) and the finest grid size of $1 \mathrm{~km}$. With a hurricanelike vortex initialized $6-7 \mathrm{~m} \mathrm{~s}^{-1}(13-14 \mathrm{hPa})$ in $V_{\text {MAX }}$ $\left(P_{\text {MIN }}\right)$ stronger than the observed, the model reproduces the observed peak intensity, but not until making landfall rather than over water and at $12 \mathrm{~h}$ later than the observed.

The next section provides a brief overview of Hurricane Patricia (2015). Section 3 describes the model configurations used for the simulation of the storm. Section 4 shows the verification of the simulated hurricane structures against multiple observations, especially those obtained during the abovementioned field campaign and flight missions. Section 5 presents a series of sensitivity simulations in order to help understand what key processes and model configurations account for the simulated extraordinary intensity and RI of Hurricane Patricia. A summary and conclusions are given in the final section.

\section{Overview}

Patricia originated from a tropical disturbance in the eastern North Pacific in mid-October, and it developed into a tropical depression at 0600 UTC 20 October 2015 after interacting with multiple weather systems, including a tropical wave over the Caribbean Sea, a gap wind event in the Gulf of Tehuantepec, and a strong Madden-Julian oscillation over the eastern Pacific (Kimberlain et al. 2016). The tropical depression gradually intensified into a wellorganized tropical storm on 21 October as it drifted westward, influenced by an easterly steering flow associated with a midlevel ridge centered over the Gulf of Mexico. The storm was located to the southwest of the high system from 1800 UTC 21 October to 0000 UTC 23 October 2015 (Fig. 1). Under the influence of a southeasterly flow, the storm moved northwestward and entered into an area with a relatively warmer water surface of over $30^{\circ} \mathrm{C}$ (Fig. 2). Patricia began to intensify rapidly in a favorable environment with very weak VWS (Rogers et al. 2017; Doyle et al. 2017), ample moisture supply from the intertropical convergence zone (ITCZ) (Fig. 1), and anomalously high SSTs (Fig. 2). In particular, Patricia experienced an 18 -h RI rate of $21 \mathrm{~m} \mathrm{~s}^{-1}(28 \mathrm{hPa})$ in $V_{\text {MAX }}$ $\left(P_{\text {MIN }}\right)$ during the period of 1800 UTC 21 October1200 UTC 22 October, followed by another 18 -h recordbreaking RI rate of $40 \mathrm{~m} \mathrm{~s}^{-1}(72 \mathrm{hPa})$ during the period of 1200 UTC 22 October-0600 UTC 23 October, intensifying into a dramatically powerful hurricane of over $95 \mathrm{~m} \mathrm{~s}^{-1}$ ( $872 \mathrm{hPa}$ ) with the RMW of less than $10 \mathrm{~km}$ (Fig. 3b).

After 1200 UTC 23 October, Patricia turned from a north-northwestward to a northeastward direction,

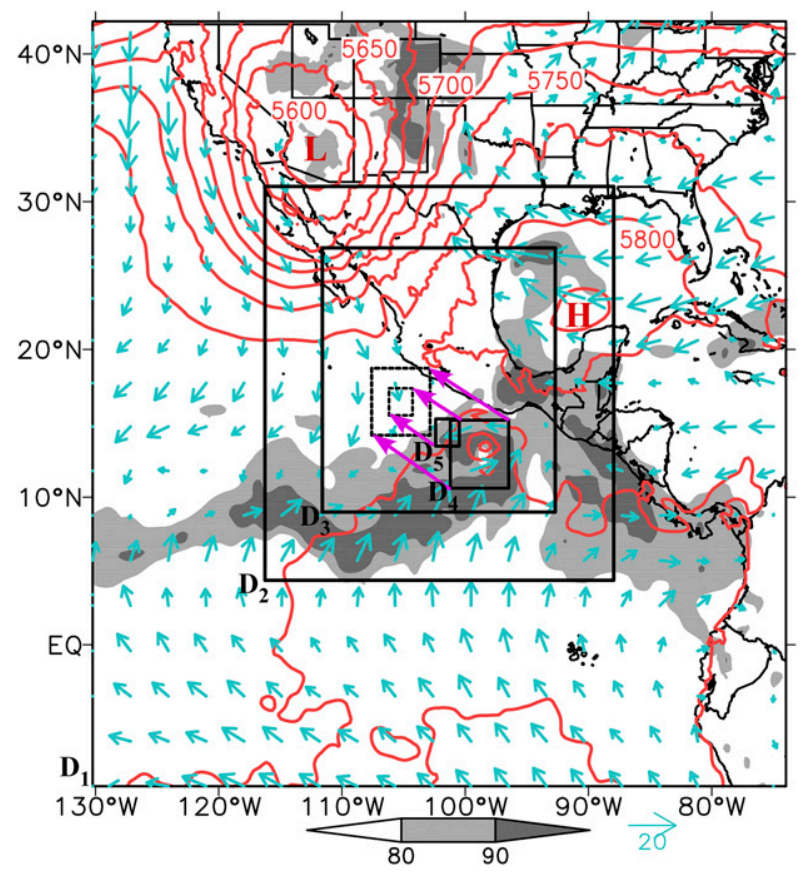

FIG. 1. Model domain configurations, superimposed with horizontal wind vectors $\left(\mathrm{m} \mathrm{s}^{-1}\right)$ at $950 \mathrm{hPa}$, the $600-900-\mathrm{hPa}$ layeraveraged relative humidity (shaded; \%), and the geopotential height (contoured at intervals of $25 \mathrm{~m}$ ) at $500 \mathrm{hPa}$ at the model initial time (i.e., 1800 UTC 21 Oct 2015). Nested domains $\mathrm{D}_{1}, \mathrm{D}_{2}, \mathrm{D}_{3}, \mathrm{D}_{4}$, and $\mathrm{D}_{5}$ have 27-, 9-, 3-, 1-, and 1/3-km horizontal grid lengths, respectively. Domains $\mathrm{D}_{4}$ and $\mathrm{D}_{5}$ move by following the storm center, with dashed domains (magenta arrows) denoting their final positions (moving directions).

affected by both a midlevel trough to its northwest and a midlevel ridge to its northeast (Kimberlain et al. 2016). These two larger-scale systems brought a relatively strong southwestward steering flow between them, resulting in the fast movement of Patricia toward the coast of Mexico. Patricia exhibited concentric eyewalls around 2027 UTC 23 October. Shortly after, the storm made landfall and weakened rapidly, with an unprecedented 128-hPa increase in $P_{\text {MIN }}$ and an $82 \mathrm{~m} \mathrm{~s}^{-1}$ decrease in $V_{\text {MAX }}$ during a 24-h period (Kimberlain et al. 2016; Rogers et al. 2017).

As part of this study, we will examine in section 4 the extent to which the WRF Model could reproduce the record-breaking intensity and extraordinary $\mathrm{RI}$ rate of Patricia and its associated mesoscale features, especially the inner-core structures, including a small-sized eye and spiral rainbands.

\section{Model description}

In this study, Hurricane Patricia (2015) is simulated using a two-way interactive, quintuply nested-grid version of the ARW-WRF (version 3.8.1; Skamarock et al. 2008) 


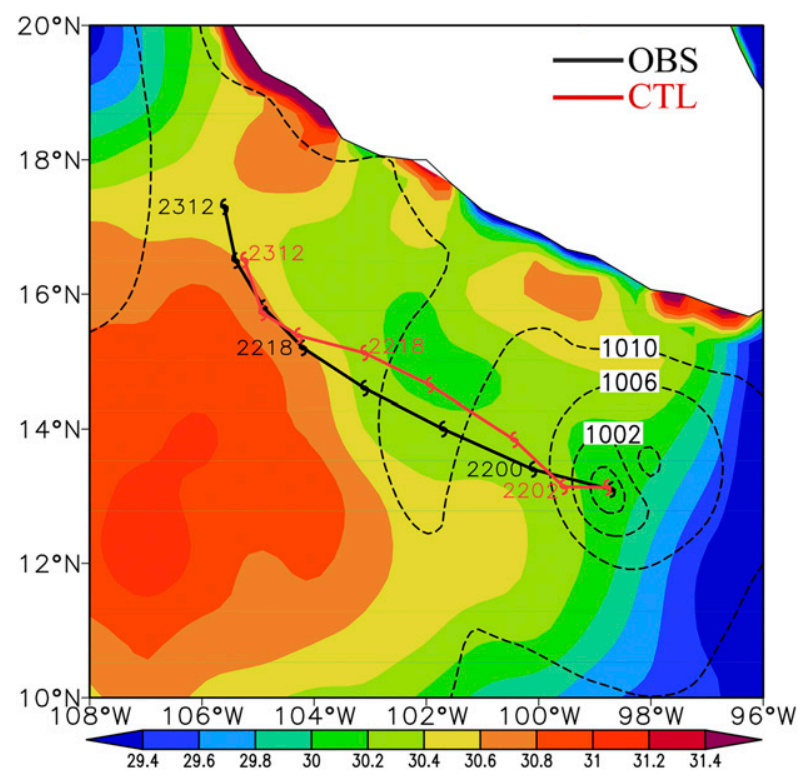

FIG. 2. Comparison of the model-simulated track (red solid) to the best track (black solid) at 6-h intervals during the 42-h period of 1800 UTC 21 Oct-1200 UTC 23 Oct 2015. Shadings and black dashed lines denote the SST from the GFS-FNL dataset $\left({ }^{\circ} \mathrm{C}\right)$ and the sea level pressure (SLP; at 4-hPa intervals), respectively, at the model initial time. The white background denotes the continental region of Mexico.

with the finest cloud-resolving resolution of $0.333 \mathrm{~km}$. Figure 1 shows the quintuply nested domains with the horizontal grid resolutions of $27,9,3,1$ and $1 / 3 \mathrm{~km}$, and $222 \times 222,334 \times 334,667 \times 667,502 \times 502$, and $607 \times 607$ grid points, respectively. The outmost domain (i.e., $\mathrm{D}_{1}$ in Fig. 1) is centered at $18.2^{\circ} \mathrm{N}, 102.1^{\circ} \mathrm{W}$, with the two innermost domains (i.e., $\mathrm{D}_{4}$ and $\mathrm{D}_{5}$ in Fig. 1 ) automatically following the movement of the vortex center. All of the domains use the same 55 vertical levels as those used by Chen et al. (2011) for the simulation of Hurricane Wilma (2005), with the model top set at $30 \mathrm{hPa}$. The outer four domains are activated at 1800 UTC 21 October, at which time Patricia strengthened into tropical storm intensity, and are integrated for $42 \mathrm{~h}$ until 1200 UTC 23 October, at which time Patricia reached its peak intensity. The innermost domain $\left(D_{5}\right)$ is initialized $16 \mathrm{~h}$ later, just a few hours prior to the observed extreme RI of Patricia (see Fig. 3a).

The initial and lateral boundary conditions are interpolated from the NCEP's GFS-FNL dataset with the horizontal resolution of $1.0^{\circ} \times 1.0^{\circ}$ at 6 -h intervals. No additional observations are incorporated into the model initial and lateral boundary conditions. All of the inner domains derive lateral boundary conditions from their corresponding parent domains. SSTs, also obtained from the GFS-FNL, are fixed during the 42-h integrations.
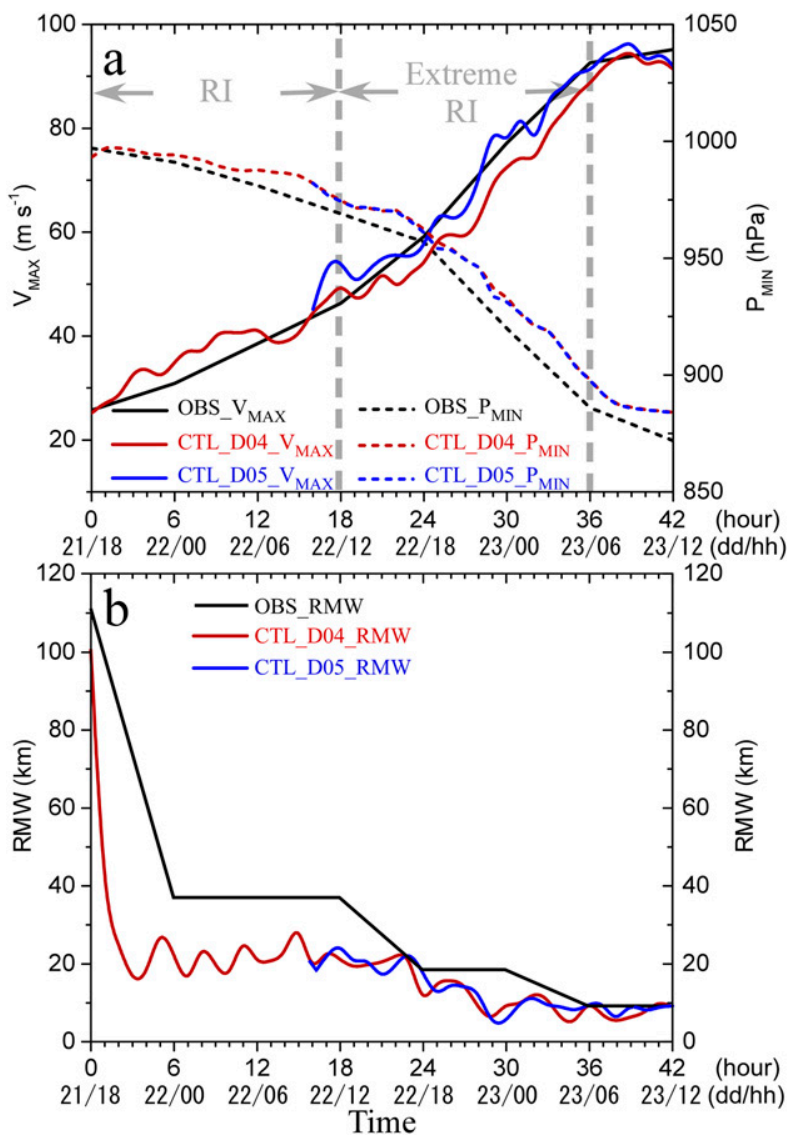

FIG. 3. Time series of the model-simulated (from the 1- and $1 / 3-\mathrm{km}$-resolution domains denoted by red and blue lines, respectively) and the observed (black) (a) $V_{\text {MAX }}$ (solid; $\mathrm{m} \mathrm{s}^{-1}$ ) and $P_{\text {MIN }}$ (dashed; hPa), and (b) the radius of $V_{\text {MAX }}(\mathrm{RMW} ; \mathrm{km}$ ) during the 42-h period of 1800 UTC 21 Oct-1200 UTC 23 Oct 2015. The observed (simulated) $V_{\text {MAX }}, P_{\text {MIN }}$, and RMW are plotted at 6 -h $(1 \mathrm{~h})$ intervals. The observed RMW comes from the extended best track dataset.

Considering that Patricia's intensity at the initial time obtained from the GFS-FNL data is too weak compared to that from the best-track data of the National Hurricane Center [i.e., $1007 \mathrm{hPa}\left(18 \mathrm{~m} \mathrm{~s}^{-1}\right)$ vs $997 \mathrm{hPa}\left(25.7 \mathrm{~m} \mathrm{~s}^{-1}\right)$ of $\left.P_{\text {MIN }}\left(V_{\text {MAX }}\right)\right]$, a 12 -h spinup initialized at 0600 UTC 21 October is conducted. After the 12-h spinup, $P_{\mathrm{MIN}}$ and $V_{\text {MAX }}$ at 1800 UTC 21 October become $997 \mathrm{hPa}$ and $24 \mathrm{~m} \mathrm{~s}^{-1}$, respectively, which are very close to those in the best track. Then, an axisymmetric hurricane vortex within a radius of $600 \mathrm{~km}$ in the GFS-FNL data at the initial time is replaced by the spun-up axisymmetric hurricane vortex of the same size, based on the dynamical initialization (DI) algorithm developed by Wang et al. (2013). In this way, any asymmetric flow component in the storm environment is still retained. It should be mentioned that we have performed sensitivity simulations, initialized with the $1.0^{\circ}$ - and $0.25^{\circ}$-resolution GFS-FNL 
data, respectively, but without applying the above DI procedure. Results reveal that the WRF Model could only capture about $80 \%$ of Patricia's total intensity change (not shown). The results indicate the importance of applying the DI procedure in obtaining the successful simulation of the extreme RI of Patricia. Applying this vortex-spinup procedure appears to be necessary in order to capture the timing of reaching the peak intensity for TCs experiencing RI either shortly after the model initiation time or during their RI stages (Liu et al. 1997; Chen et al. 2011; Fox and Judt 2018).

The model physics schemes include (i) the new Thompson et al. (2008) cloud microphysics scheme; (ii) the Yonsei University PBL scheme with the revised MM5 Monin-Obukhov surface layer scheme (Hong et al. 2006); (iii) the Rapid Radiative Transfer Model (RRTM) for longwave radiation (Mlawer et al. 1997) and the Dudhia shortwave scheme for shortwave radiation (Dudhia 1989); (iv) the Betts-Miller-Janjić (Betts 1986; Betts and Miller 1986; Janjić 1994) cumulus parameterization scheme that is used only for the outmost domain (i.e., $\mathrm{D}_{1}$ ); and (v) the Donelan et al. (2004) drag coefficient for the horizontal momentum fluxes over warm water.

\section{Model verification}

Before using the model simulation to gain insight into various processes leading to the RI and extraordinary intensity as well as the inner-core structures of Patricia, it is highly desirable to verify the model-simulated results against as many observations as possible. For this purpose, Fig. 2 compares first the 42-h model-simulated [hereafter referred to as the control run (CTL)] and the best track of Hurricane Patricia (2015). In general, the WRF Model reproduces the northwestward movement of Hurricane Patricia, except that the simulated track moves slower than observed in the first 6-h integration, and then it shifts rightward away from the best track with a distance error of about $46 \mathrm{~km}$ during 0000 UTC 22 October-0000 UTC 23 October and with a 6-h delay at the end of the 42-h integrations. This slower speed bias appears to be attributable to the presence of a weaker midlevel high pressure system over the Gulf of Mexico than that in the GFS-FNL dataset. Namely, the model underestimates the intensity of the midlevel ridge, resulting in a weaker steering flow for the movement of the storm.

Particularly encouraging is that the model simulation captures extremely well the intensity changes of Patricia in both $P_{\text {MIN }}$ and $V_{\text {MAX }}$ (Fig. 3a). Specifically, Patricia experienced an RI rate of $1.6 \mathrm{hPah}^{-1}\left(1.2 \mathrm{~m} \mathrm{~s}^{-1} \mathrm{~h}^{-1}\right)$ during the first 18 -h period, followed by another 18 -h extreme RI with an unprecedented rate of $4.6 \mathrm{hPa} \mathrm{h}^{-1}$ $\left(2.6 \mathrm{~m} \mathrm{~s}^{-1} \mathrm{~h}^{-1}\right)$, and then a 6 -h period of slower intensification. These two RI stages are well reproduced in the CTL run, showing the intensification rates of $1.3 \mathrm{hPah}^{-1}\left(1.2 \mathrm{~m} \mathrm{~s}^{-1} \mathrm{~h}^{-1}\right)$ and $4.5 \mathrm{hPah}^{-1}\left(2.5 \mathrm{~m} \mathrm{~s}^{-1} \mathrm{~h}^{-1}\right)$, respectively, from the 1-km resolution domain (i.e., $\mathrm{D}_{4}$ ). The simulated Patricia reaches its peak intensity of $884 \mathrm{hPa}$ in $P_{\text {MIN }}$ and $92 \mathrm{~m} \mathrm{~s}^{-1}$ in $V_{\mathrm{MAX}}$, albeit $12 \mathrm{hPa}$ and $3 \mathrm{~m} \mathrm{~s}^{-1}$ weaker than the observed. However, the $1 / 3-\mathrm{km}$-resolution domain $\left(\mathrm{D}_{5}\right)$ data show that the model reproduces near exactly the extreme RI rate of $2.6 \mathrm{~m} \mathrm{~s}^{-1} \mathrm{~h}^{-1}$ during the second 18 -h period, indicating the significance of using higher grid resolutions in TC intensity forecasts, which will be examined in section 5a. It is important to note that the extreme RI stages in both the observations and the simulation occur when the storm centers are closer to a region of higher SSTs (i.e., up to $31.2^{\circ} \mathrm{C}$ ) to the west (cf. Figs. 3a and 2). This closeness with respect to the warm pool appears to explain why the observed extreme RI stage is better reproduced than the earlier RI stage, during which period the simulated storm moves across a relatively lower SST region than that in the observed. The closeness can also explain why the model captures well the observed turning point (i.e., at $t=18 \mathrm{~h}$ ) of RI to an extreme RI stage. We may mention that the CTL simulation also captures the observed double-eyewall structures after extending its integration to $60 \mathrm{~h}$. However, these results are not shown here, because we focus solely on the extraordinary intensity and RI of Patricia in this study.

Figure $3 \mathrm{~b}$ shows that the simulated RMW contracts rapidly during the first 6-h RI stage, and then remains nearly steady around $20 \mathrm{~km}$ until $24 \mathrm{~h}$ into the extreme RI stage, followed by another contraction and steady cycle during the remaining 18-h integrations. Although the simulated RMWs are about $16 \mathrm{~km}$ smaller than the observed during the first RI stage, the general trends of contraction and steady states are all reproduced, especially the small-sized RMW of less than $10 \mathrm{~km}$. The slow changes and steady state of the RMWs during Patricia's RI stages are consistent with those found in the previous modeling and observational studies (Chen et al. 2011; Kieu 2012; Wang and Wang 2014; Stern et al. 2015; Qin et al. 2016).

Figure 4 compares qualitatively the simulated composite radar reflectivity to the infrared images from the GOES-15 satellite during Patricia's three different stages: the first RI stage (Figs. 4a and $4 \mathrm{~d}$, at $t=6 \mathrm{~h}$ ), the extreme RI stage (Figs. $4 \mathrm{~b}$ and $4 \mathrm{e}$, at $t=24 \mathrm{~h}$ ), and the peak intensity time (Figs. $4 \mathrm{c}$ and $4 \mathrm{f}$, at $t=42 \mathrm{~h}$ ). At $t=6 \mathrm{~h}$, Patricia displayed highly asymmetric inner-core structures with two intense spiral rainbands denoted by $\mathrm{A} 1$ and $\mathrm{B} 1$ in 

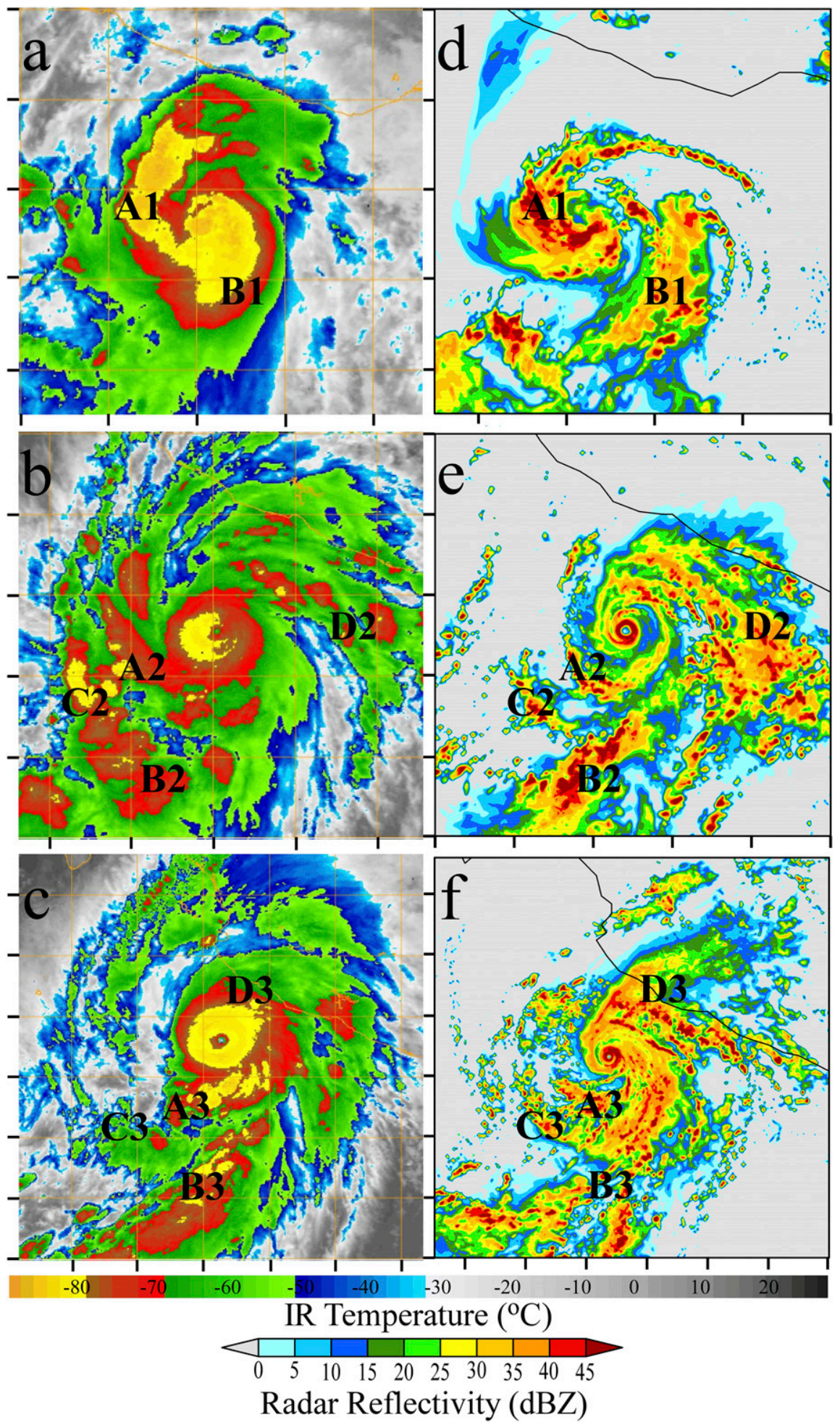

FIG. 4. Comparison of (left) the infrared images from the GOES-15 satellite to (right) the simulated composite radar reflectivity at (a),(d) 0000 UTC 22 Oct $(t=6 \mathrm{~h}$, during RI), (b),(e) 1800 UTC 22 Oct ( $t=24 \mathrm{~h}$, during the extreme RI stage), and (c),(f) 1200 UTC 23 Oct ( $t=42 \mathrm{~h}$, at the peak intensity time). Letters A1-A3, B1-B3, C2 and C3, and D2 and D3 denote the major spiral rainbands at the three different stages of Patricia's development in order to facilitate the model verifications against the observations. The intervals of $2^{\circ}$ in latitude and longitude are used for the $x$ and $y$ coordinates in (a)-(f). 

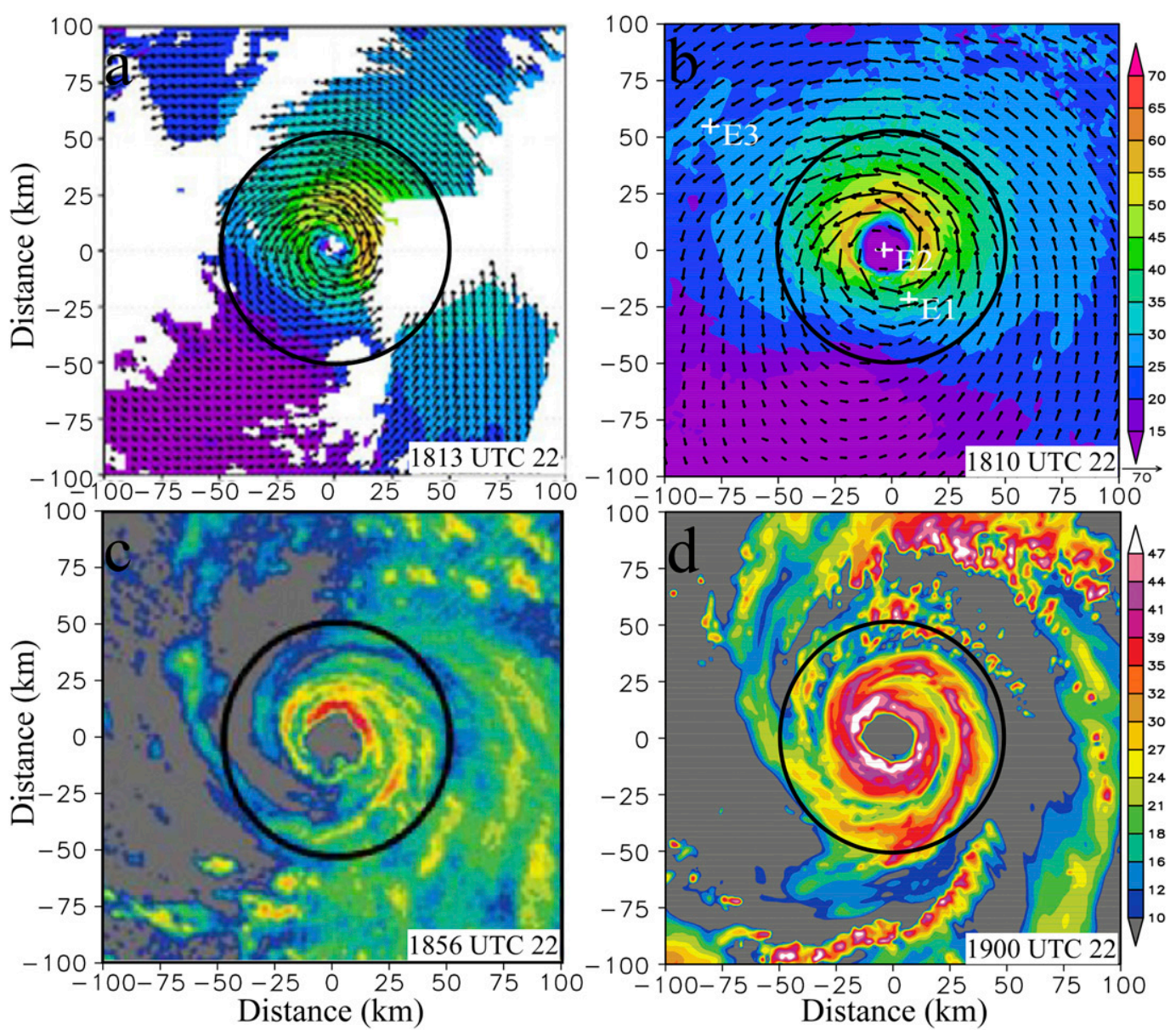

FIG. 5. Comparison of (left) the observed and (right) the model-simulated horizontal wind vectors and speeds [shaded in (a) and (b); $\mathrm{m} \mathrm{s}^{-1}$ ] at 2-km altitude, and the radar reflectivity [shaded in (c) and (d); dBZ] at 2.8-km altitude. Results are for (a) 1813 UTC 22 Oct and (c) 1856 UTC 22 October 2015 during the WP-3D mission [adapted from Rogers et al. (2017)] and for (b) 1810 UTC 22 Oct and (d) 1900 UTC Oct 2015 during the simulation. Black circles denote the radius of $50 \mathrm{~km}$ from the storm center. Letters E1, E2, and E3 in (b) denote the locations of soundings shown in Fig. 7.

Figs. 4a and 4d, respectively, extending clockwise from the eyewall into the northeastern quadrant, and southwestward into the ITCZ. After $18 \mathrm{~h}$, Patricia intensified into an intense hurricane showing a clear small-sized eye; a robust eyewall with higher cloud tops, especially in the western semicircle; and a large coverage area of deep convection consisting of four major spiral rainbands, labeled from A2 to D2. Note that the development of the robust eyewall convection and rainband $\mathrm{C} 2$ took place over the higher-SST regions (cf. Figs. 4b and 2). At Patricia's peak intensity stage, Fig. $4 \mathrm{c}$ shows the development of a very small-sized eye surrounded by a near-uniform eyewall of intense convective clouds, which was wrapped by several well-defined rainbands. Note that the southwestern tails of rainbands B1-B3 have always been located in the ITCZ, even after the storm moved northwestward for more than $700 \mathrm{~km}$ (cf. Figs. 4a-c and Fig. 1), indicating the important role of the moisture supply from the ITCZ in feeding these rainbands and likely contributing to the RI of the storm.

A comparison between Figs. $4 \mathrm{~d}-\mathrm{f}$ and $4 \mathrm{a}-\mathrm{c}$ reveals that the model reproduces the distributions of all the major rainbands described above, with one-to-one correspondence of $\mathrm{A} 1$ and $\mathrm{B} 1$ during the first 18-h RI stage; A2, B2, C2, and D2 during the extreme RI stage; and $\mathrm{A} 3, \mathrm{~B} 3, \mathrm{C} 3$, and D3 at the peak intensity time. In particular, the model mimics Patricia's small pinhole eye surrounded with a narrow intense convective ring during the extreme RI and peak intensity stages. The simulated inner-core structures are much finer than results previously obtained, for example, in the simulations of Hurricanes Andrew 
(Liu et al. 1997; Yau et al. 2004) and Wilma (Chen et al. 2011), due to the use of higher grid resolutions herein.

It is fortunate that the U.S. Navy's TCI field campaign (Doyle et al. 2017) and NOAA's P-3 missions (Rogers et al. 2017) obtained ample high quality observational data, in addition to satellite images, that can be used to verify the simulated structures of Patricia. Figure 5 compares the observed horizontal wind field and radar reflectivity during the WP-3D mission of Patricia's extreme RI stage to the model simulated that are taken close to the time used for Figs. 4 b,e. The field observations are fine enough to resolve the small-sized eye, the eyewall, several spiral rainbands that are similar to A2, B2, and D2 in Fig. 4b, and a highly asymmetric wind field with the strong and weak winds located in the northeast and southwest semicircles, respectively (Figs. 5a,c). It is apparent that the CTL simulation reproduces well the asymmetric wind pattern and the eyewall size or the RMW of less than $25 \mathrm{~km}$ (cf. Figs. 5b,d and 5a,c). Moreover, CTL captures the compact eye, the intense eyewall, and the abovementioned rainbands.

Figure 6 compares the observed radial profile of the flight-level wind speeds to those simulated at the same time as in Fig. 5. We see an asymmetric wind across the storm center from the northeast to southwest, which coincides with the structures shown in Fig. 5a. The maximum wind of around $60 \mathrm{~m} \mathrm{~s}^{-1}$, located $15 \mathrm{~km}$ radially away to the northeast of the storm center, is well captured by CTL even though the radius of the simulated maxima is $5 \mathrm{~km}$ larger (Fig. 6a). CTL also reproduces another peak wind of about $50 \mathrm{~m} \mathrm{~s}^{-1}$ at about $10 \mathrm{~km}$ away to the southwest of the storm center. Similarly, CTL reproduces the sharp radial wind profiles along the southeast-northwest cross section, including the two peaks at the RMW contracting to around $10 \mathrm{~km}$ from the storm center on both sides. The observations and the CTL results are both characterized by flat wind profiles beyond the radii of $60 \mathrm{~km}$ during this extreme RI stage.

Vertical profiles of the simulated temperature, dewpoint temperature, and relative humidity taken in the eyewall, the eye center, and the vicinity of an outer rainband are compared in Fig. 7 to dropsondes obtained by the reconnaissance flight. We see saturated conditions in the eyewall, especially for levels below $850 \mathrm{hPa}$ with the relative humidity of nearly $100 \%$, in both the observations and the simulation (cf. Figs. 7a and 7d). This saturated column coincides with the development of intense eyewall convection shown in Figs. 4b and 4c. The observed eye showed a thick inversion layer from around 875 to $775 \mathrm{hPa}$, with a nearly $75-\mathrm{hPa}$ boundary layer depth below and a dry layer above to $700 \mathrm{hPa}$

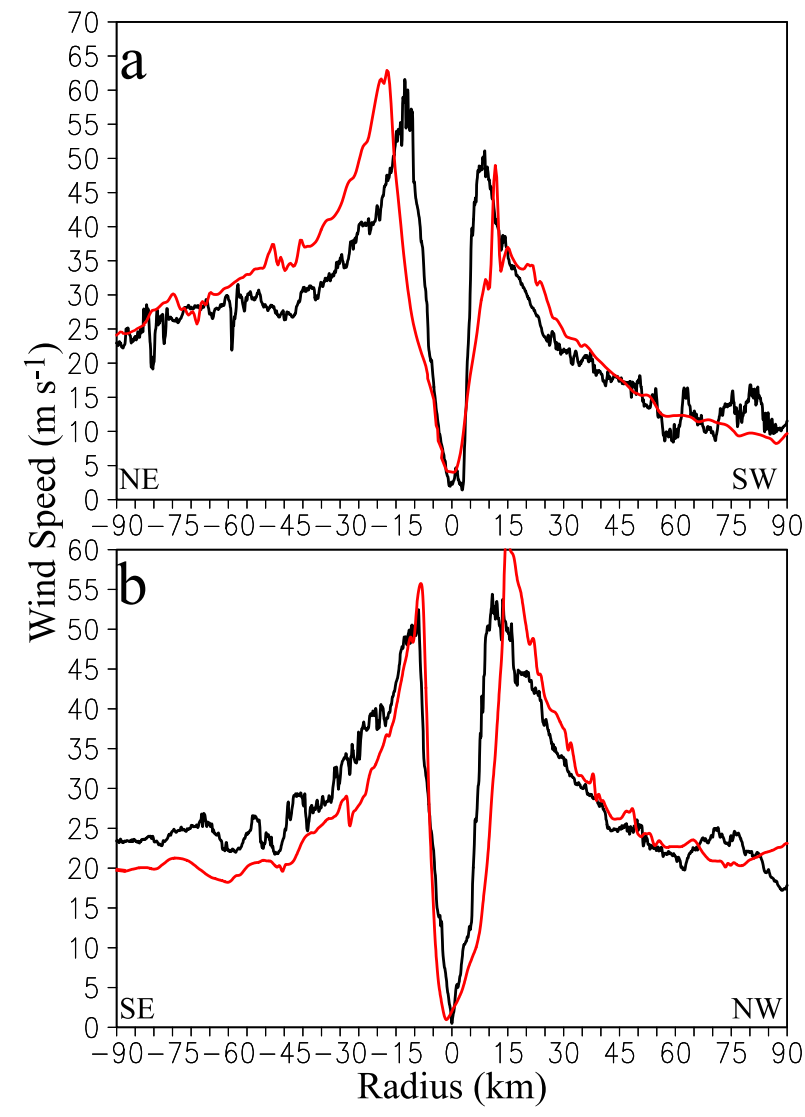

FIG. 6. Radial profiles of the flight-level (near $3 \mathrm{~km}$ from aircraft of WP-3D, N43RF) wind speeds $\left(\mathrm{m} \mathrm{s}^{-1}\right)$ from the observations (black) and simulation (red) near (a) 1740 UTC 22 Oct and (b) 1855 UTC 22 Oct 2015.

(Fig. 7b). It is evident from Fig. 7e that the model simulation reproduces reasonably well the inversion layer and the deep dry layer, except that the simulated inversion layer is $50 \mathrm{hPa}$ deeper than the observations. CTL also produces pronounced subsidence in the eye region during the extreme RI stage (not shown), which is consistent with the work of Rogers et al. (2017), who showed the generation of an intense warm core of over $20^{\circ} \mathrm{C}$ around 2000 UTC 23 October. Figure $7 \mathrm{c}$ shows moister conditions below $700 \mathrm{hPa}$ in the outer rainband than those in the eye but less saturated than the eyewall region, which are all captured by the simulation (Fig. 7f).

Figure 8 compares the vertical cross section of the azimuthal-mean radar reflectivity and the tangential wind between the observations and the simulation. At 1813 UTC 22 October (near $t=24 \mathrm{~h}$ ), the observed peak azimuthal-mean tangential wind was over $45 \mathrm{~m} \mathrm{~s}^{-1}$, located between 15 - and $19-\mathrm{km}$ radius from the TC center. This is consistent with the RMW series shown in Fig. 3b. The eyewall with higher radar reflectivity tilted slightly 

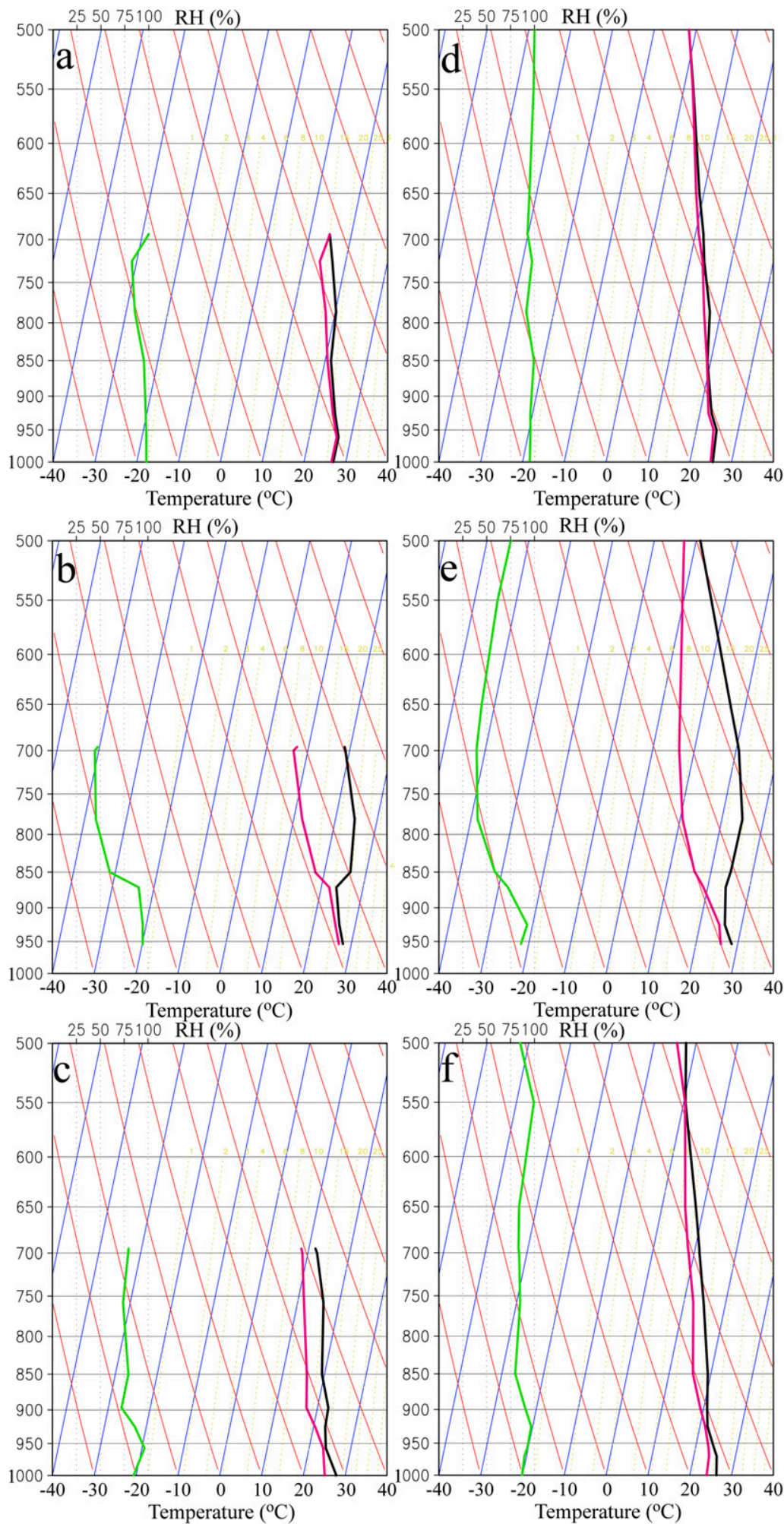

FIG. 7. Skew $T-\log p$ diagrams of the soundings taken (a),(d) in the eyewall at 1800 UTC, (b),(e) in the eye at 1900 UTC, and (c),(f) near an outer rainband at 2000 UTC 22 Oct from (left) the aircraft (WP-3D, N43RF) observations and (right) the simulations. Black, magenta, and green lines denote the temperature $\left({ }^{\circ} \mathrm{C}\right)$, dewpoint temperature $\left({ }^{\circ} \mathrm{C}\right)$, and relative humidity (\%), respectively. 

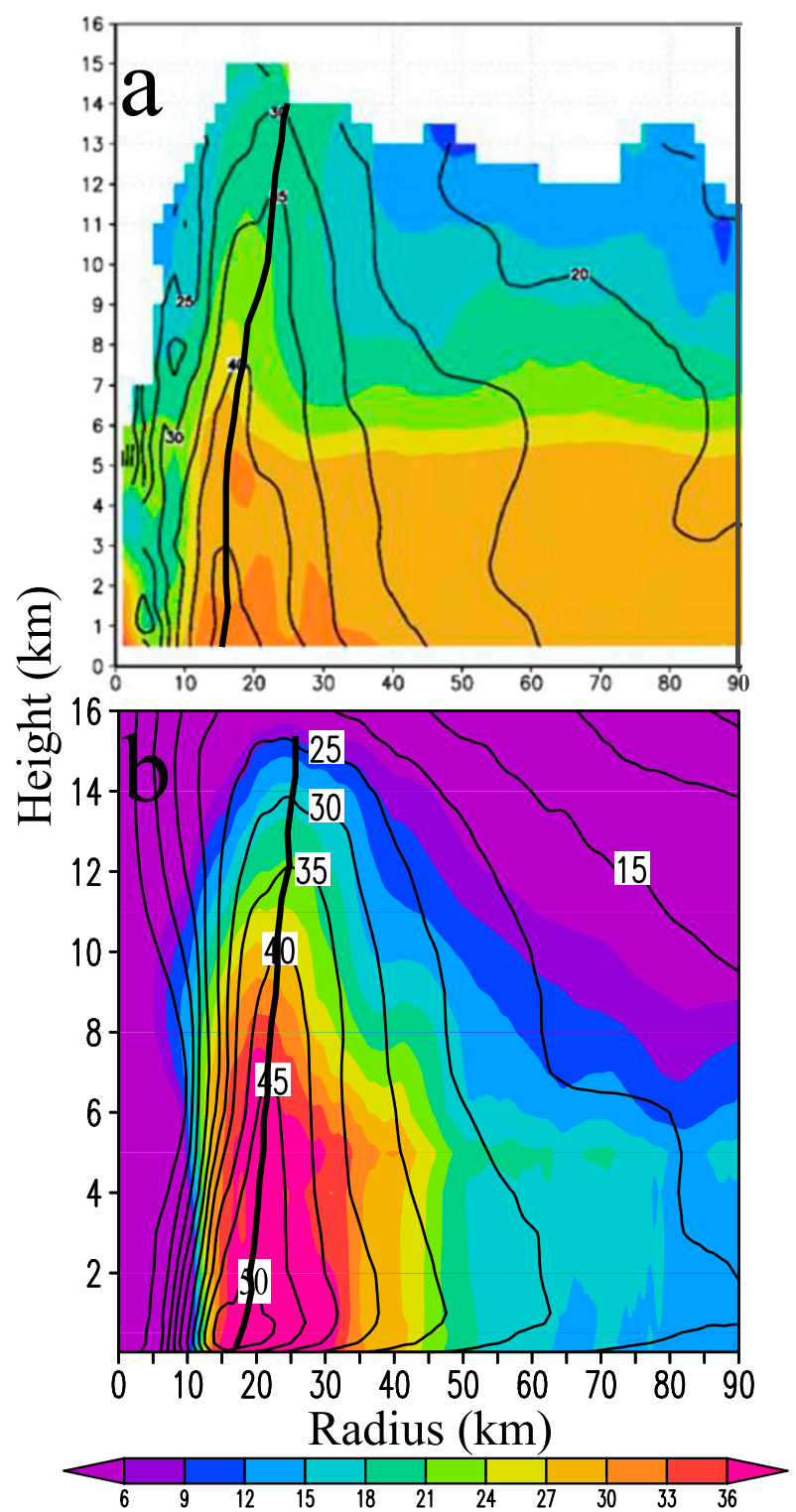

FIG. 8. Radius-height cross sections of (a) the observed and (b) the simulated azimuthal-mean radar reflectivity (shaded; $\mathrm{dBZ}$ ) and tangential wind (contour; $\mathrm{m} \mathrm{s}^{-1}$ ), which are taken at 1813 and 1810 UTC 22 Oct, respectively. Solid black lines denote the RMW.

outward with only $10-\mathrm{km}$ radial differences from the surface to $15-\mathrm{km}$ altitude, while the high radar reflectivity $(>24 \mathrm{dBZ})$ extended farther outward below $6-\mathrm{km}$ height. It is notable that the compact eyewall with small RMWs and high radar reflectivity is well reproduced by the WRF. However, the simulated eyewall in terms of both the wind speed and the radar reflectivity is somewhat stronger near the RMWs than those in the observations (cf. Figs. 8a,b), which are due likely to the different biases between the modeled and observed reflectivities. In fact, the observations might not collect all the inner-core wind information, especially near the RMW, due to its coarse spatial resolution. Moreover, the best-track data showed that $V_{\text {MAX }}$ was around $59 \mathrm{~m} \mathrm{~s}^{-1}$ around that time, which is comparable to the intensity shown in Fig. 8b. Thus, the observed azimuthal-mean tangential wind in Fig. 8a might have underestimated Patricia's intensity substantially.

The above model verifications show clearly that the WRF Model reproduces reasonably well the observed inner-core structures of Patricia during the TCI field campaign and NOAA's WP-3D mission, including the small-sized eye, the eyewall, and the distribution of various spiral rainbands. These results are indeed encouraging, when considering that the model is initialized with the GFS-FNL data without incorporating any additional observations. This implies that many innercore structures (and intensity and track) within Patricia could be reasonably well simulated from the given large-scale flow fields if reasonable initial vortex intensity and model physics as well as grid resolutions are used. This implication will be demonstrated in the next section through a series of sensitivity simulations. Moreover, the model output data can be utilized to diagnose some unobservable features in the next and future studies.

\section{Sensitivity simulations}

After presenting the successful simulation of Patricia in the preceding section, it is of interest to examine its sensitivities to various model configurations and physical processes in order to help understand which model configurations are essential in reproducing Patricia's extreme intensity and RI rate. For this purpose, a total of 11 sensitivity simulations in the following three categories are conducted: (i) horizontal and vertical resolutions, (ii) SSTs, and (iii) cloud microphysics, in which all the model configurations are identical to those in the CTL run except for the sensitivity parameters to be examined. All the sensitivity simulations produce tracks for Patricia that are similar to the CTL simulation, indicating that Patricia's track is controlled mainly by the large-scale flows, as expected. Thus, in the next section, we will focus on the different intensities and RI rates of the storms obtained from the above sensitivity simulations.

\section{a. Effects of horizontal and vertical resolutions}

During our initial experimentation, we noted increased intensities of the storms as the horizontal resolution was increased. Similar results are seen in the 
TABLE 1. Model configuration of sensitivity simulations.

\begin{tabular}{lcccccccc}
\hline \hline \multicolumn{1}{c}{ Expt } & $\mathrm{D}_{1}(27 \mathrm{~km})$ & $\mathrm{D}_{2}(9 \mathrm{~km})$ & $\mathrm{D}_{3}(3 \mathrm{~km})$ & $\mathrm{D}_{4}(1 \mathrm{~km})$ & $\mathrm{D}_{5}(1 / 3 \mathrm{~km})$ & Vertical levels & Microphysics & SST $\left({ }^{\circ} \mathrm{C}\right)$ \\
\hline CTL & Yes & Yes & Yes & Yes & Yes & 55 & New Thompson & GFS \\
H3km & Yes & Yes & Yes & No & No & 55 & New Thompson & GFS \\
$\mathrm{H} 1 \mathrm{~km}$ & Yes & Yes & Yes & Yes & No & 55 & New Thompson & GFS \\
V41 & Yes & Yes & Yes & Yes & Yes & 41 & New Thompson & GFS \\
V73 & Yes & Yes & Yes & Yes & Yes & 73 & New Thompson & GFS \\
W0.5 & Yes & Yes & Yes & Yes & Yes & 55 & New Thompson & SST + 0.5 \\
C0.5 & Yes & Yes & Yes & Yes & Yes & 55 & New Thompson & SST -0.5 \\
MP $_{\text {LIN }}$ & Yes & Yes & Yes & Yes & Yes & 55 & Lin & GFS \\
MP $_{\text {WSM6 }}$ & Yes & Yes & Yes & Yes & Yes & 55 & WSM6 & GFS \\
MP $_{\text {GCE }}$ & Yes & Yes & Yes & Yes & Yes & 55 & Goddard GCE & GFS \\
MP $_{\text {Morrison }}$ & Yes & Yes & Yes & Yes & Yes & 55 & Morrison & GFS \\
MP $_{\text {WDM6 }}$ & Yes & Yes & Yes & Yes & Yes & 55 & WDM6-WRF & GFS \\
\hline
\end{tabular}

simulations of Hurricanes Andrew of 1992 (Yau et al. 2004), Ivan of 2004 (Gentry and Lackmann 2010), and Wilma of 2005 (Chen et al. 2011). Previous studies have also shown the pronounced sensitivity of hurricane intensity to the vertical resolution (e.g., Zhang and Wang 2003; Kimball and Dougherty 2006; Zhang et al. 2015). Thus, two experiments deal with the use of coarser horizontal resolutions in the finest-resolution domain of $1 \mathrm{~km}$ in a quadruply nested grid (i.e., 27/9/3/ $1 \mathrm{~km}$ ) and $3 \mathrm{~km}$ in a triply nested grid (i.e., 27/9/3 km), which are referred to as $\mathrm{H} 1 \mathrm{~km}$ and $\mathrm{H} 3 \mathrm{~km}$, respectively (see Table 1). [Note that the NCEP's Hurricane WRF (HWRF) Model uses 3-km resolution for its operational forecasts of Hurricane Patricia.] Another two experiments deal with the use of different vertical resolutions: a coarser one and a finer one of 41 and
73 vertical levels, which are referred to as V41 and V73, respectively. Figures 9a and 9b show that despite their different resolutions, V41 and V73 share the same $\Omega$ vertical distribution as that in CTL, with higher resolutions in both the lower and upper levels, but relatively coarse resolutions in the midtroposphere. For fair comparisons with the CTL run, 12-h dynamical spinups are rerun for V41 and V73, respectively, in order for the initial vortex intensity and the subsequent spinup to be as similar as possible to those in the CTL simulation.

Figure 10 compares the time series of the simulated $P_{\mathrm{MIN}}$ and $V_{\mathrm{MAX}}$ results from different horizontal- and vertical-resolution runs to the CTL simulated results. In general, all the runs exhibit slight differences in both $P_{\text {MIN }}$ and $V_{\text {MAX }}$ from CTL during the first 18 -h

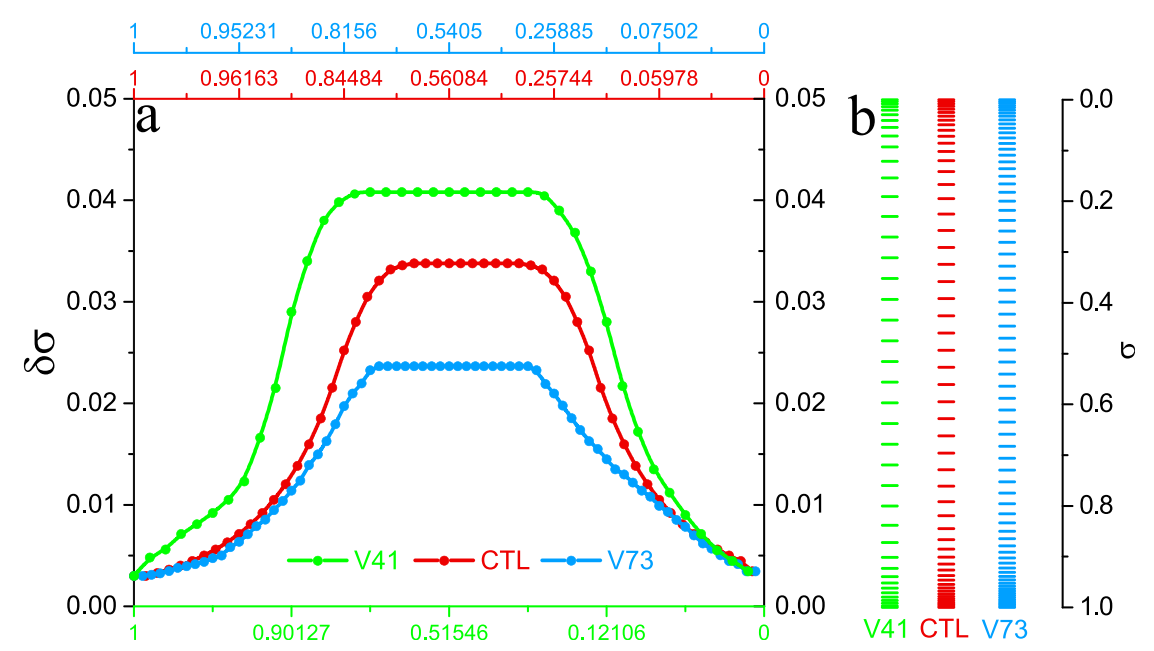

FIG. 9. (a) Distribution of the vertical resolution $\delta \sigma$ as a function of vertical levels $\sigma$ and (b) $\sigma$ for the 41- (green; V41), 55- (red; CTL), and 73-level (blue; V73) simulations. In (a), the values of the $\sigma$ levels for CTL (red), V73 (blue), and V41 (green) are given above and below the frame, respectively. 


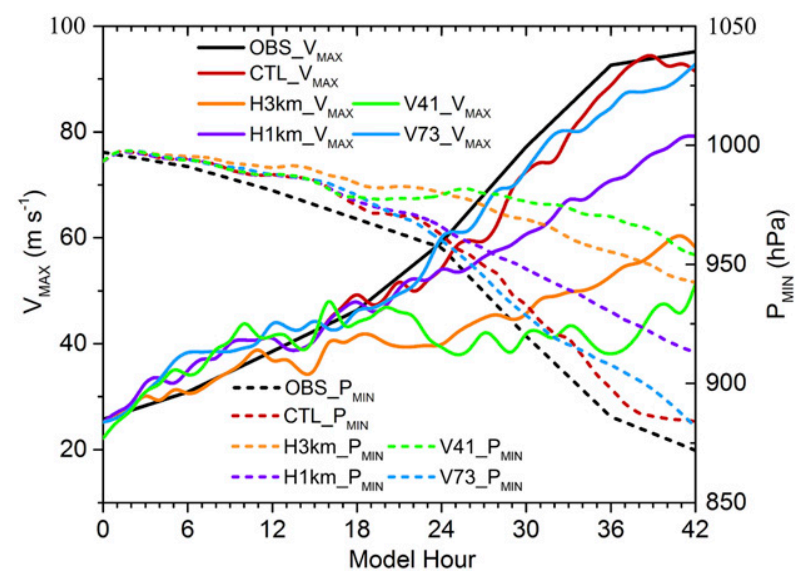

FIG. 10. As in Fig. 3a, but for $V_{\text {MAX }}$ (solid) and $P_{\text {MIN }}$ (dashed) from the observations, CTL, and the sensitivity simulations due to varying horizontal and vertical resolutions: OBS (black), CTL (red), H3km (orange), H1km (purple), V41 (green), and V73 (blue), which are plotted at 1 -h intervals.

integration except for $\mathrm{H} 3 \mathrm{~km}$, which shows notably slower RI rates, but increasing differences during the second 18-h integration, except for V73, which shows similar extreme RI rates. Apparently, decreasing the horizontal resolution fails to capture the extreme RI rate and the peak intensity, even with the finest grid size of $1 \mathrm{~km}$. The peak intensities from $\mathrm{H} 3 \mathrm{~km}$ and $\mathrm{H} 1 \mathrm{~km}$ are about $58 \mathrm{~m} \mathrm{~s}^{-1}(943 \mathrm{hPa})$ and $79 \mathrm{~m} \mathrm{~s}^{-1}$ $(913 \mathrm{hPa})$, respectively, as compared to the CTLsimulated result of $92 \mathrm{~m} \mathrm{~s}^{-1}(884 \mathrm{hPa})$. The intensity differences are consistent with the differences in storm size and convective organization simulated in CTL, $\mathrm{H} 3 \mathrm{~km}$, and $\mathrm{H} 1 \mathrm{~km}$. Figure 11 shows that increasing the horizontal resolution from 3 to 1 and $1 / 3 \mathrm{~km}$ results in decreased eye/eyewall sizes, narrower eyewall widths, and better-resolved convective activity in the eyewall and spiral rainbands as well as more small-scale convective elements (cf. Figs. 11a,c,d). Clearly, the eyewall and spiral rainband structures are very sensitive to the horizontal resolution. The same conclusion was also reached by Yau et al. (2004) in their simulation of Hurricane Andrew (1992).

Note that the peak $V_{\text {MAX }}$ from $\mathrm{H} 3 \mathrm{~km}$, which is close to that predicted by HWRF with the finest resolution of $3 \mathrm{~km}$ (Tallapragada et al. 2014; Kimberlain et al. 2016), only captures about $60 \%$ of the observed $95 \mathrm{~m} \mathrm{~s}^{-1}$ intensity. Fox and Judt (2018) also reached the same conclusion that $3-\mathrm{km}$ resolution is too coarse to capture the peak intensity of Patricia. These results help explain why the operational model with its current horizontal grid resolution could not capture rapidly intensifying TCs with such an extreme rate and peak intensity. It follows that given a favorable large-scale environment, a subkilometer horizontal resolution is needed in order to reproduce such an extremely intensifying TC.

Like the sensitivity simulations of Zhang and Wang (2003) and Zhang et al. (2015), coarsening vertical resolution tends to produce weaker storms. This is clearly seen in V41, which shows the weakest intensity of about $50 \mathrm{~m} \mathrm{~s}^{-1}(952 \mathrm{hPa})$; it even exhibits only a slight deepening during the extreme RI stage. This can be attributed to the presence of much weaker convective organization in the eyewall and spiral rainbands in V41 than that in CTL, resulting in a poorly defined eye (cf. Figs. 11a,b). All these results indicate that (i) appropriate vertical resolution is still needed even when the finest horizontal resolution has increased to $1 / 3 \mathrm{~km}$ and (ii) increasing the vertical resolution is equivalent to increasing the horizontal resolution in TC intensity forecasts (Zhang et al. 2015), which can also be seen by comparing the results of V41 and H3km to those of CTL. On the other hand, increasing the vertical resolution from 41 to 73 levels nearly doubles the peak $V_{\text {MAX }}$. So, V73 reproduces quite well the extreme RI rate, with the general trends and intensity changes similar to those of CTL. This implies that using 55 vertical levels in CTL is close to the "saturation" point in reproducing the extreme intensity, although the TC intensity forecasts are sensitive to the distribution of the vertical levels (Zhang et al. 2015).

\section{b. Effects of varying SSTs}

As mentioned in section 4, Patricia's extreme RI occurs when its center is close to the higher SSTs to its west. Thus, two sensitivity simulations with different SSTs are performed in order to test the dependence of Patricia's extreme RI on SST. These simulations are done by increasing and decreasing the initial two-dimensional SST field by $0.5^{\circ} \mathrm{C}$, referred to as W0.5 and C 0.5 , respectively, and keeping it fixed during the 42-h integration as done in CTL. In some sense, the possible results in the W0.5 and C0.5 simulations may be viewed as if Patricia moves about $50-100 \mathrm{~km}$ to the west and east of the best track, respectively, since its track is distributed nearly normal to the SST gradients (see Fig. 2). In particular, we wish to ask: Will Patricia experience such extreme RI if the SST field over the eastern Pacific were just $0.5^{\circ} \mathrm{C}$ uniformly colder? Although it is well known that higher SSTs favor the development of intense TCs (Holliday and Thompson 1979; Elsner et al. 2013), especially in terms of the maximum potential intensity (Emanuel 1986, 1997; Elsner et al. 2008), it is still unclear how to quantify the RI rates of TCs for the given high SST alone. 


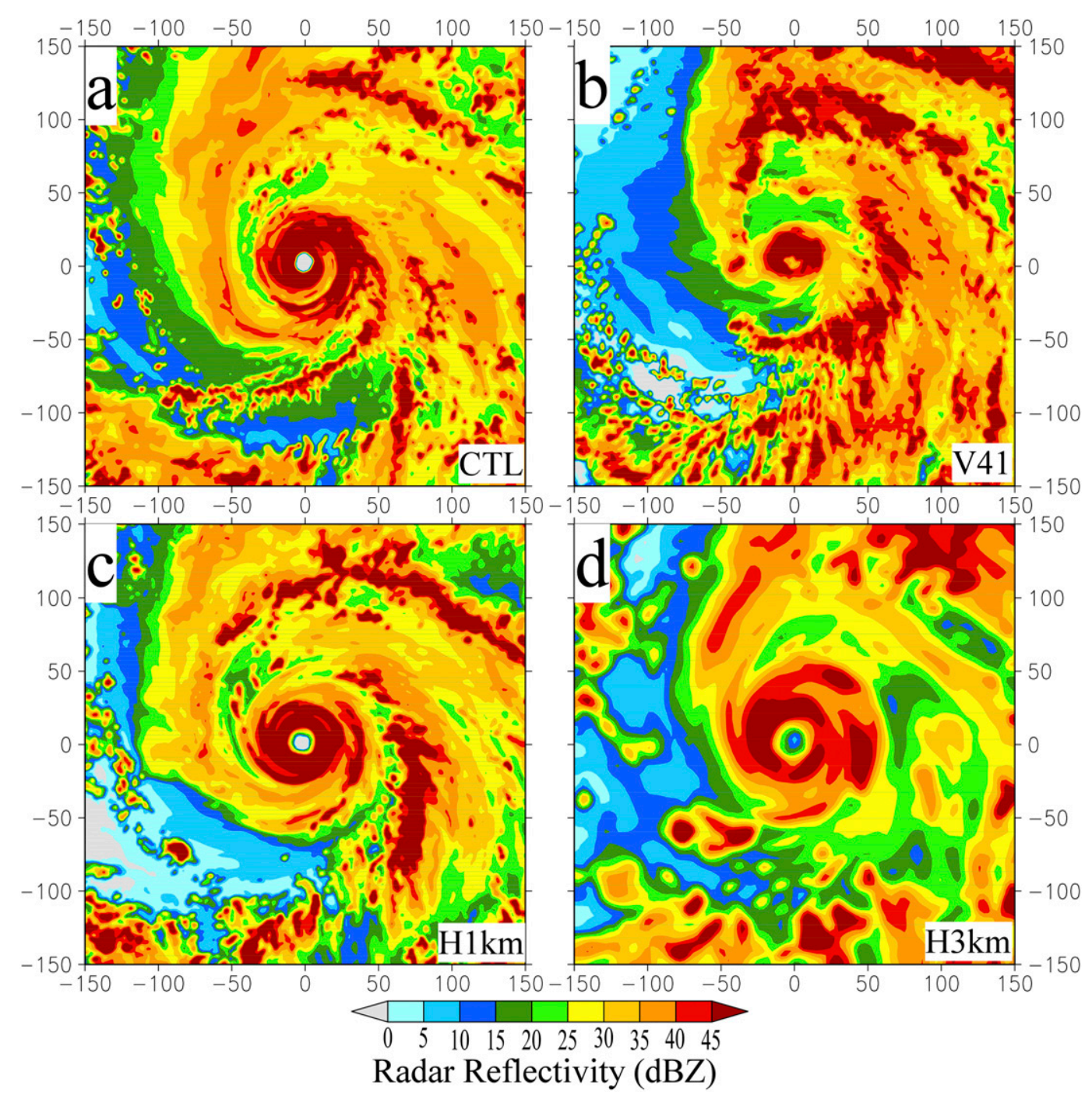

FIG. 11. Comparison of the composite radar reflectivity over a $300 \mathrm{~km} \times 300 \mathrm{~km}$ area centered at the eye from the 42-h integrations between (a) CTL, (b) V41, (c) H1 km, and (d) H3km.

Figure 12 shows that increasing or decreasing SSTs changes the storm intensity little during the first 10-12-h integrations. This result is attributable partly to the likely adjustment of air temperature and moisture in the PBL to the changed underlying SSTs, at least, during the first few hours of integrations. Subsequently, the C0.5 storm deviates markedly from the CTL example, which is our major concern. That is, a $0.5^{\circ} \mathrm{C}$ decrease in SSTs results in a slight intensification during the second 18-h integration, with the peak intensity of about $45 \mathrm{~m} \mathrm{~s}^{-1}(967 \mathrm{hPa})$ in $V_{\mathrm{MAX}}\left(P_{\mathrm{MIN}}\right)$. Interestingly, an RI stage begins at $t=35 \mathrm{~h}$ when both CTL and the observed storm are about to cease RI. On the other hand, a $0.5^{\circ} \mathrm{C}$ increase in SST does not increase the already extreme $\mathrm{RI}$ rate in CTL during the second 18-h integration. Although it is about $40 \mathrm{~m} \mathrm{~s}^{-1}(58 \mathrm{hPa})$ stronger than the
C0.5 storm at $t=35 \mathrm{~h}$, the W0.5 storm experiences a 6-h period of rapid weakening subsequently, which is opposite to the trend of the $\mathrm{C} 0.5$ storm. These results suggest that the relationship between TC intensity and SST is highly nonlinear and that higher SSTs do not always lead to the development of more intense TCs, even though the other conditions are all favorable. Michaels et al. (2006) also found that TC peak intensities drop somewhat when the SST increases (to more than $29^{\circ} \mathrm{C}$ ).

A close-up examination of the model simulations suggests that the abovementioned nonlinear relationship has something to do with the different eyewall sizes or rainband structures among the CTL, W0.5, and C 0.5 storms. Specifically, the CTL storm shows a contracting RMW, followed by a nearly steady RMW from $t=24$ to 


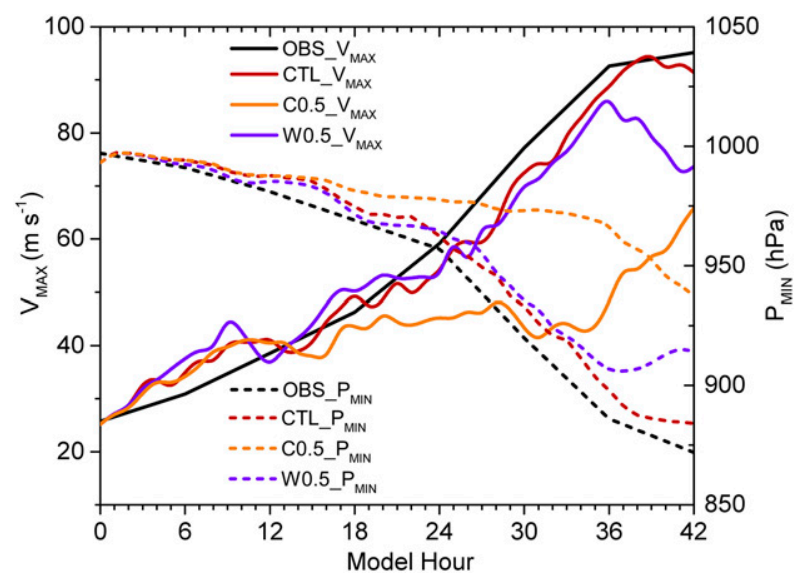

FIG. 12. As in Fig. 3a, but for $V_{\text {MAX }}$ (solid) and $P_{\text {MIN }}$ (dashed) from the observations, CTL, and the sensitivity simulations due to varying SSTs: OBS (black), CTL (red), W0.5 (purple), and C0.5 (orange), which are plotted at 1-h intervals.

$42 \mathrm{~h}$ (Fig. 3b). This is also true for the W0.5 storm until $t=35 \mathrm{~h}$, after which time the eyewall size expands considerably likely due to the development of an intense rainband (denoted by W in Fig. 13d) that is embedded in a widespread convective area to the east (cf. Figs. 13a, $\mathrm{b}$ and $13 \mathrm{c}, \mathrm{d}$ ). This rainband and widespread convection tends to consume moisture that would be otherwise transported into the eyewall region (Wang 2009; Chen and Zhang 2013; Zhu and Zhu 2014), leading to the subsequent weakening of the storm (Fig. 12). In contrast, the C0.5 storm exhibits a much larger eyewall size than that in W0.5 (and CTL) at $t=35 \mathrm{~h}$ (cf. Figs. 13a, $13 \mathrm{c}$, and $13 \mathrm{e}$ ), but it starts contracting subsequently as it moves northwestward into a relatively higher SST region (Fig. 2), likely accounting for the RI of the storm.

\section{c. Effects of various cloud microphysics schemes}

Given the influences of the inner-core cloud structures on the storm intensity, as shown in the preceding subsection, it is of interest to examine how different cloud microphysics schemes could affect the simulated extreme intensity and intensity changes of Patricia. In fact, some previous studies have revealed that varying microphysical processes or parameterization schemes would affect the structures and evolution of TCs (e.g., Braun and Tao 2000; Zhu and Zhang 2006; Pattnaik and Krishnamurti 2007; Morrison et al. 2009). The WRF Model contains more than 10 cloud microphysics options, most of which have been used to study the development of TCs and other mesoscale convective systems (Liu et al. 1997; McFarquhar et al. 2006; Li and $\mathrm{Pu}$ 2008; Pattnaik and Krishnamurti 2007; Tao et al. 2011; Zheng et al. 2016; Penny et al. 2016). In this study, six cloud microphysics options, including the one used in CTL, are selected to test their sensitivities to Patricia's intensity and inner-core structures with the finest resolution of $333 \mathrm{~m}$. These options are $\mathrm{MP}_{\text {LIN }}$

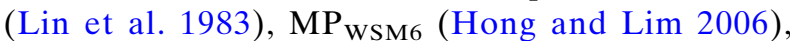
$\mathrm{MP}_{\mathrm{GCE}}$ (Tao et al. 1989), $\mathrm{MP}_{\text {Morrison }}$ (Morrison et al.

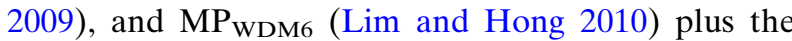
CTL simulation (Thompson et al. 2008). All of these schemes contain six classes of hydrometeors: water vapor, cloud water, rain, snow, ice, and graupel. In addition, $\mathrm{MP}_{\mathrm{LIN}}, \mathrm{MP}_{\mathrm{WSM}}$, and $\mathrm{CTL}$ are one-moment schemes containing the mixing ratios of the hydrometeors, while the others are two-moment schemes predicting both the mixing ratios and the number concentrations of the hydrometeor species.

It is apparent from Fig. 14 that on average differences in $V_{\text {MAX }}$ may be seen among the six runs, despite some notable departures in $P_{\mathrm{MIN}}$, during the first 18-h integrations. Subsequently, increasing differences in Patricia's intensifying rates occur among all the runs, ranging from a relatively slower intensification rate until $t=32 \mathrm{~h}$ in $\mathrm{MP}_{\text {Morrison }}$ to an even faster RI rate in $\mathrm{MP}_{\text {LIN }}$ than that simulated in CTL but an RI rate similar to that in their first 18-h periods in $\mathrm{MP}_{\mathrm{GCE}}$ and $\mathrm{MP}_{\mathrm{WDM}}$. Thus, only $\mathrm{MP}_{\mathrm{LIN}}$ (and CTL) can reproduce both the extreme $\mathrm{RI}$ rate and peak intensity. In fact, $\mathrm{MP}_{\mathrm{LIN}}$ consistently produces the strongest storm throughout the 42-h integrations, whereas $\mathrm{MP}_{\mathrm{GCE}}$ becomes the weakest storm at the end of the simulation due to its rapid weakening in the final few hours. Otherwise, $\mathrm{MP}_{\text {Morrison }}$ would generate the weakest storm if it does not encounter an extreme RI stage during the final 6-h integrations. The largest intensity differences between the strongest and weakest storms are about $42 \mathrm{~m} \mathrm{~s}^{-1}(56 \mathrm{hPa})$ between $\mathrm{MP}_{\mathrm{LIN}}$ and $\mathrm{MP}_{\text {Morrison }}$ at $t=32 \mathrm{~h}$, and about $35 \mathrm{~m} \mathrm{~s}^{-1}(52 \mathrm{hPa})$ between $\mathrm{MP}_{\mathrm{LIN}}$ and $\mathrm{MP}_{\mathrm{GCE}}$ at $t=42 \mathrm{~h}$.

The above results indicate that the one-moment microphysics schemes appear to mimic better Patricia's extreme RI and peak intensity than the two-moment schemes. This is different from the previous studies of squall lines (e.g., Morrison et al. 2009; Diao et al. 2017), in which twomoment schemes do better than one-moment schemes in reproducing the associated rainfall structures, especially the trailing stratiform precipitation. The result of the most intense storm with the extreme RI produced by $\mathrm{MP}_{\mathrm{LIN}}$ is not surprising, based on the work of $\mathrm{Li}$ and $\mathrm{Pu}$ (2008) and Tao et al. (2011), who found that $\mathrm{MP}_{\text {LIN }}$ tends to produce more rainwater (and likely graupel) that falls faster than the other cloud ice/water particles in vertical columns such that hydrostatic water loading is reduced and updrafts become strong.

To see the influences of varying microphysics schemes on the inner-core structures, two representative 


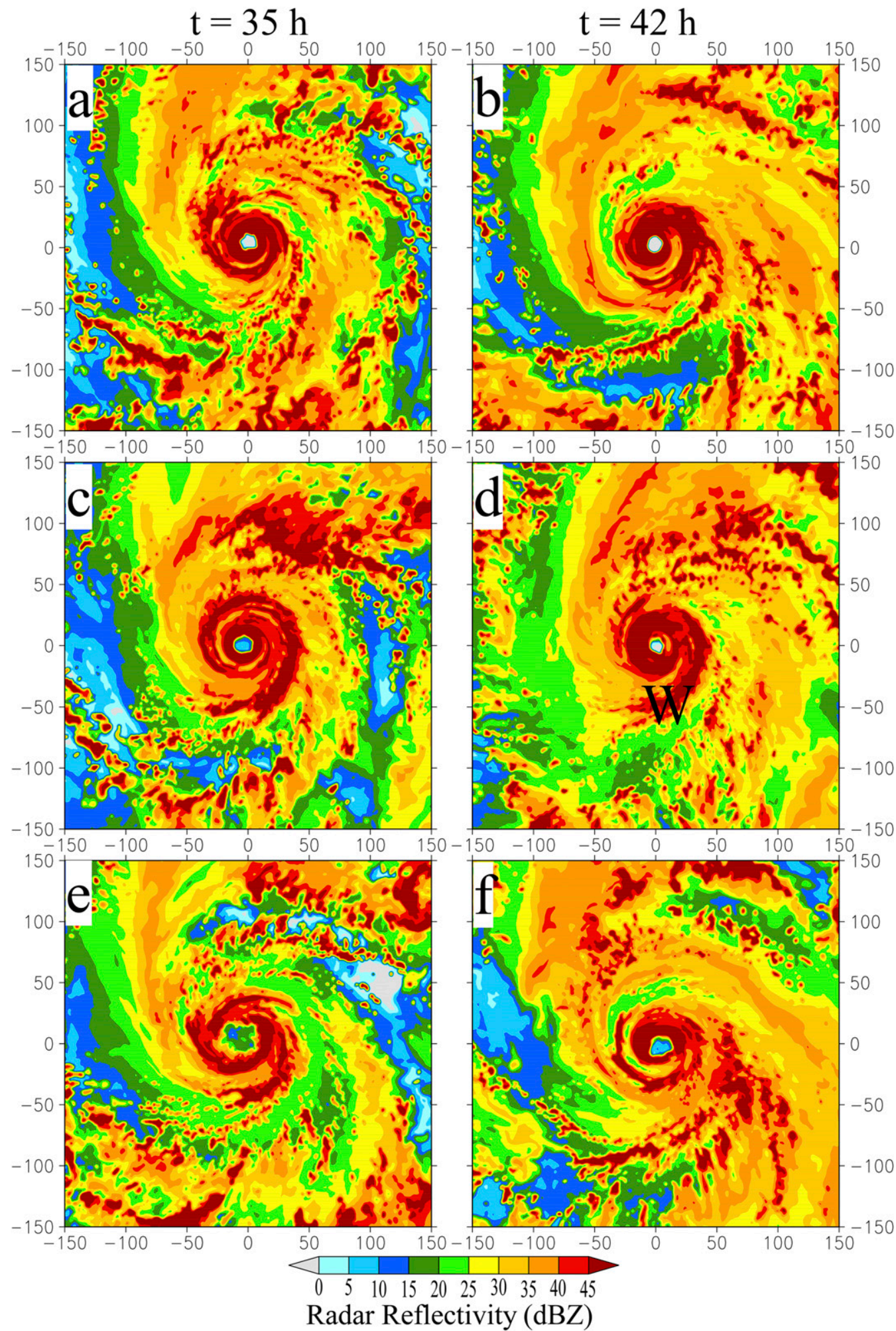

FIG. 13. As in Fig. 11, but from the (left) 35- and (right) 42-h integrations of the 1-km resolution domain between (a),(b) CTL, (c),(d) W0.5, and (e),(f) the C0.5 simulations. The letter W in (d) denotes a rainband that may account for the weakening of the storm (see text). 


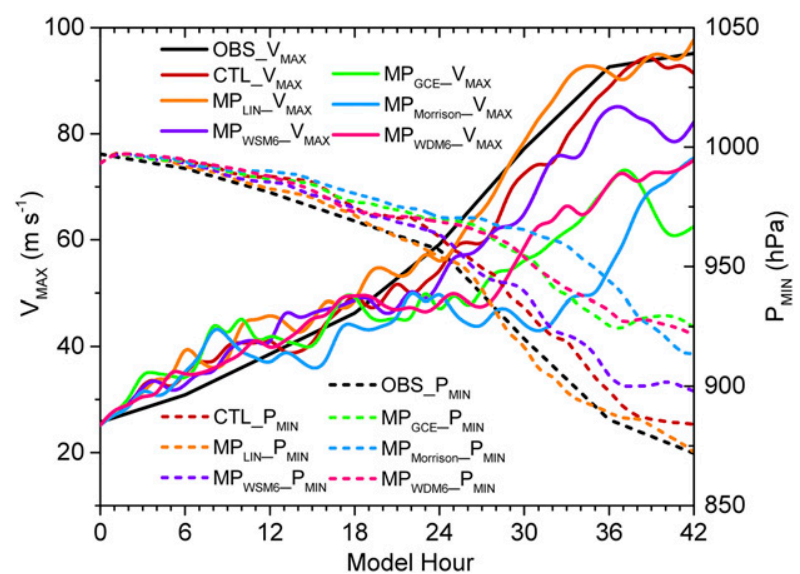

FIG. 14. As in Fig. 3a, but for $V_{\text {MAX }}$ (solid) and $P_{\text {MIN }}$ (dashed) from the observations, CTL, and the sensitivity simulations due to varying microphysics schemes: OBS (black), CTL (red), $\mathrm{MP}_{\mathrm{LIN}}$ (orange), $\mathrm{MP}_{\mathrm{WSM}}$ (purple), $\mathrm{MP}_{\mathrm{GCE}}$ (green), $\mathrm{MP}_{\text {Morrison }}$ (blue), and $\mathrm{MP}_{\text {WDM6 }}$ (magenta), which are plotted at 1-h intervals.

sensitivity simulations, that is, $\mathrm{MP}_{\mathrm{LIN}}$ and $\mathrm{MP}_{\text {Morrison }}$, are presented in Fig. 15. It is evident that $\mathrm{MP}_{\mathrm{LIN}}$ produces much less stratiform or weak convective precipitation with fewer rainbands in the outer region but a more intense and wider eyewall than those in all the other simulations. The former scenario facilitates the inward transport of moist energy into the eyewall, while the latter implies the presence of more latent heat release, resulting partly from the increased energy supply from the outer region, and partly from more rainfall fallouts and less water loading, as mentioned before. Both would contribute positively to the storm's RI, as expected from the previous studies. The opposite scenarios are true for $\mathrm{MP}_{\text {Morrison, }}$, showing widespread stratiform precipitation and more rainbands in the outer region but a narrower eyewall with less intense convective activity (Figs. 15c,d). At the end of the 42-h integrations, the eyewall is even encircled by an outer spiral rainband, indicating its subsequent weakening.

\section{Summary and conclusions}

In this study, a successful 42-h simulation of Hurricane Patricia (2015), initialized with GFS-FNL data only, is obtained using a two-way interactive, quintuply nestedgrid version of the WRF Model with the finest resolution of $333 \mathrm{~m}$. Results show that the control simulation reproduces Patricia's track, extraordinary peak intensity, and record-breaking intensification rate. That is, the simulated peak intensity of $92 \mathrm{~m} \mathrm{~s}^{-1}(884 \mathrm{hPa})$ compares well to the observed $95 \mathrm{~m} \mathrm{~s}^{-1}(872 \mathrm{hPa})$. In particular, the model simulates Patricia's first 18-h RI with an hourly intensification rate of $1.2 \mathrm{~m} \mathrm{~s}^{-1} \mathrm{~h}^{-1}\left(1.3 \mathrm{hPah}^{-1}\right)$, followed by another 18-h extreme RI with an unprecedented hourly intensification rate of $2.5 \mathrm{~m} \mathrm{~s}^{-1}$ $\left(4.5 \mathrm{hPa} \mathrm{h}^{-1}\right)$; namely, with an $18-\mathrm{h}$ RI rate of $21.6 \mathrm{~m} \mathrm{~s}^{-1}$ $(23.4 \mathrm{hPa})$, followed by another 18 -h extreme RI rate of $45 \mathrm{~m} \mathrm{~s}^{-1}(81 \mathrm{hPa})$, respectively. A high correlation between Patricia's RI rates and SST is found; that is, the extreme RI rate occurs as the storm moves toward higher SST regions, and the RI rate decreases subsequently, as it moves away from the higher SST regions. The model also reproduces an intense warmcored eye with a deep dry layer above an inversion, a small-sized moist eyewall with the RMW of less than $10 \mathrm{~km}$, vertical thermal structures in the outer regions, the radial profiles of horizontal winds at the flight level, and the distribution of major spiral rainbands during Patricia's earlier RI, extreme RI, and peak intensity stages, as verified against various observations from the TCI field campaign and NOAA's P-3 missions as well as satellite images.

A series of sensitivity tests within the context of varying grid resolutions, SSTs, and cloud microphysics schemes is performed to examine what parameters are essential in reproducing Patricia's extreme intensity and RI rate. Results show that reproducing Patricia's extreme RI and peak intensity requires subkilometer horizontal resolutions and vertical resolutions of over 50 levels and that increasing the vertical resolution up to 55 levels in the present case is equivalent to increasing the horizontal resolution. Moreover, Patricia's eye/eyewall sizes, and convective organization in the eyewall and spiral rainbands, which are closely related to its intensity and intensity changes, are very sensitive to the horizontal and vertical resolutions.

While decreasing the SST by $0.5^{\circ} \mathrm{C}$ everywhere results in a slow intensification during the first 36 -h integrations, followed by a 6-h RI, increasing the SST by $0.5^{\circ} \mathrm{C}$ produces only slight differences in the intensity changes compared with those in CTL, but results in a rapid weakening during the final 6-h integrations. The results suggest that in the current model configurations the relationship between the TC intensity and SST is highly nonlinear and that higher SSTs do not always lead to more intense TCs.

An analysis of the model-simulated radar reflectivity reveals that the distribution and intensity of spiral rainbands, especially near the inner-core regions; the eyewall contraction; and the eyewall final size determine the RI rate and final intensity of the storm. It is found that the model with different cloud microphysics schemes could produce intensity differences as large as $42 \mathrm{~m} \mathrm{~s}^{-1}(56 \mathrm{hPa})$ and pronounced differences in the distribution and intensity of spiral rainbands, 


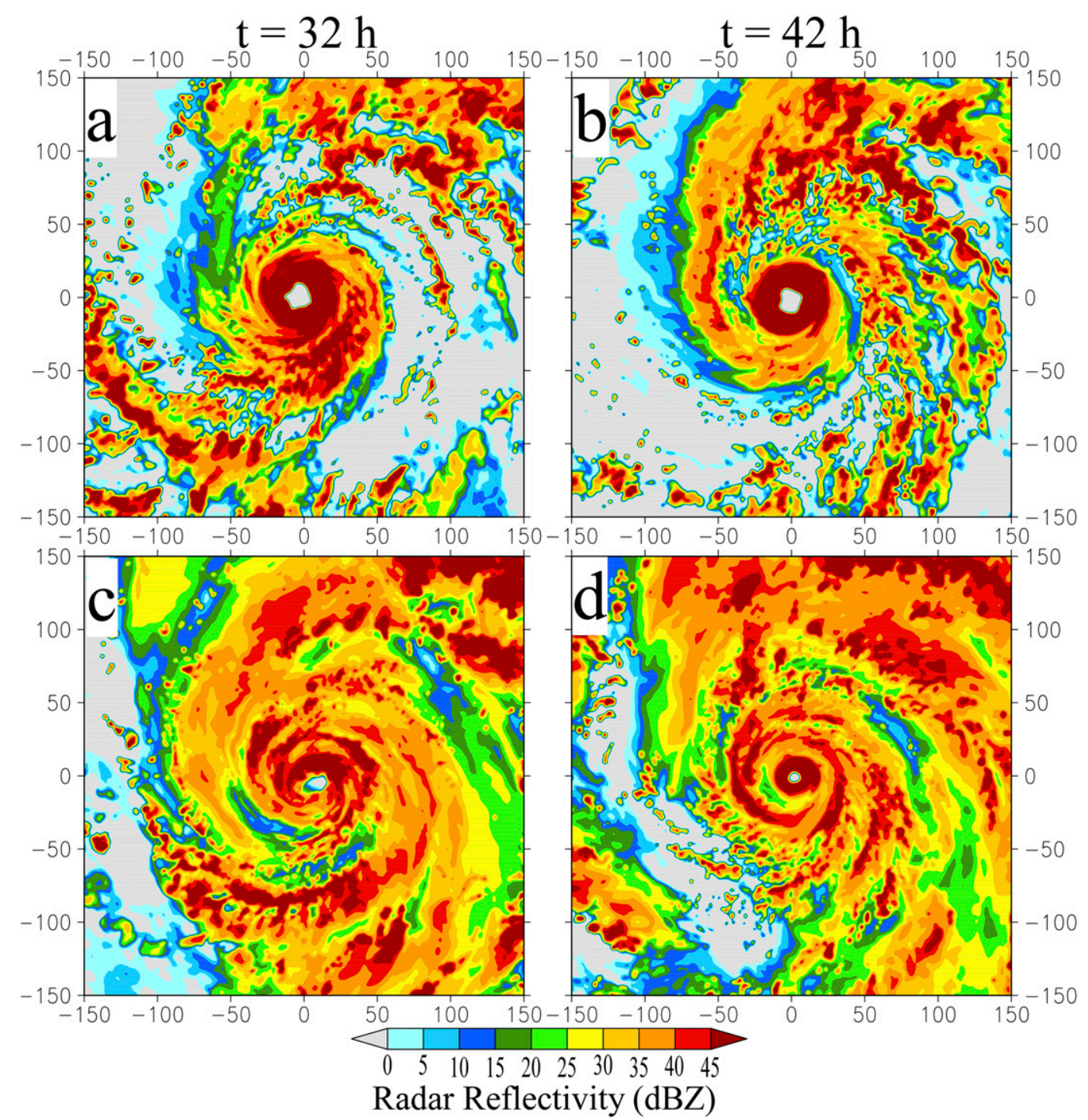

FIG. 15. As in Fig. 11, but from the (left) 32-and (right) 42-h integrations of the 1-km resolution domain between the (a),(b) $\mathrm{MP}_{\mathrm{LIN}}$ and (c),(d) $\mathrm{MP}_{\text {Morrison }}$ simulations.

eyewall convection and width, and their associated stratiform precipitation. In general, one-moment microphysics schemes appear to reproduce better Patricia's extreme RI and peak intensity than the two-moment schemes.

Based on the above results, we may conclude that Patricia's extraordinary peak intensity and record-breaking intensification rate as well as its eyewall size and spiral rainband structures are determined more or less by largescale meteorological conditions including warm SST, weak VWS, the moist ITCZ, and convective organization in the inner-core region. Similar results have also been obtained from many of the previous modeling studies of other TCs (e.g., Hurricanes Andrew, 1992; Katrina, 2005; and
Wilma, 2005; and Typhoon Megi, 2010). All these results suggest that given realistic large-scale conditions and initial vortex intensity and structures, it is possible to reasonably reproduce the record-breaking RI rates and extreme peak intensity as well as many inner-core structures of TCs, like Patricia, if ultrahigh horizontal resolution with appropriate model physics schemes is incorporated.

Acknowledgments. This work was funded by U.S. Office of Navy Research Grants N000141410143 and N000141712210. The numerical simulations were conducted on Deepthought 2 of the University of Maryland. 


\section{REFERENCES}

Betts, A. K., 1986: A new convective adjustment scheme. Part I: Observational and theoretical basis. Quart. J. Roy. Meteor. Soc., 112, 677-691, https://doi.org/10.1002/qj.49711247307.

, and M. J. Miller, 1986: A new convective adjustment scheme. Part II: Single column tests using GATE wave, BOMEX, and Arctic air-mass data sets. Quart. J. Roy. Meteor. Soc., 112, 693 709, https://doi.org/10.1002/qj.49711247308.

Braun, S. A., and W.-K. Tao, 2000: Sensitivity of high-resolution simulations of Hurricane Bob (1991) to planetary boundary layer parameterizations. Mon. Wea. Rev., 128, 3941-3961, https://doi.org/ 10.1175/1520-0493(2000)129<3941:SOHRSO > 2.0.CO;2.

Carrasco, C., C. Landsea, and Y. Lin, 2014: The influence of tropical cyclone size on its intensification. Wea. Forecasting, 29, 582-590, https://doi.org/10.1175/WAF-D-13-00092.1.

Chen, H., and D.-L. Zhang, 2013: On the rapid intensification of Hurricane Wilma (2005). Part II: Convective bursts and the upper-level warm core. J. Atmos. Sci., 70, 146-162, https://doi.org/ 10.1175/JAS-D-12-062.1.

- — - J. Carton, and R. Atlas, 2011: On the rapid intensification of Hurricane Wilma (2005). Part I: Model prediction and structural changes. Wea. Forecasting, 26, 885-901, https://doi.org/10.1175/WAF-D-11-00001.1.

Diao, M., G. H. Bryan, H. Morrison, and J. B. Jensen, 2017: Ice nucleation parameterization and relative humidity distribution in idealized squall-line simulations. J. Atmos. Sci., 74, 2761-2787, https://doi.org/10.1175/JAS-D-16-0356.1.

Donelan, M. A., B. K. Haus, N. Reul, W. J. Plant, M. Stiassnie, H. C. Graber, O. B. Brown, and E. S. Saltzman, 2004: On the limiting aerodynamics roughness on the ocean in very strong winds. Geophys. Res. Lett., 31, LI18306, https://doi.org/10.1029/2004GL019460.

Doyle, J. D., and Coauthors, 2017: A view of tropical cyclones from above: The Tropical Cyclone Intensity (TCI) experiment. Bull. Amer. Meteor. Soc., 98, 2113-2134, https://doi.org/10.1175/ BAMS-D-16-0055.1.

Dudhia, J., 1989: Numerical study of convection observed during the Winter Monsoon Experiment using a mesoscale twodimensional model. J. Atmos. Sci., 46, 3077-3107, https://doi.org/ 10.1175/1520-0469(1989)046<3077:NSOCOD>2.0.CO;2.

Elsner, J. B., J. P. Kossin, and T. H. Jagger, 2008: The increasing intensity of the strongest tropical cyclones. Nature, 455, 92-95, https://doi.org/10.1038/nature07234.

— S. E. Strazzo, T. H. Jagger, T. LaRow, and M. Zhao, 2013: Sensitivity of limiting hurricane intensity to SST in the Atlantic from observations and GCMs. J. Climate, 26, 59495957, https://doi.org/10.1175/JCLI-D-12-00433.1.

Emanuel, K. A., 1986: An air-sea interaction theory for tropical cyclones. Part I: Steady-state maintenance. J. Atmos. Sci., 43, 585-605, https://doi.org/10.1175/1520-0469(1986)043<0585: AASITF $>2.0 . \mathrm{CO} ; 2$.

- 1997: Some aspects of hurricane inner-core dynamics and energetic. J. Atmos. Sci., 54, 1014-1026, https://doi.org/10.1175/ 1520-0469(1997)054<1014:SAOHIC > 2.0.CO;2.

Fox, K. R., and F. Judt, 2018: A numerical study on the extreme intensification of Hurricane Patricia (2015). Wea. Forecasting, 33, 989-999, https://doi.org/10.1175/WAF-D-17-0101.1.

Gentry, M. S., and G. M. Lackmann, 2010: Sensitivity of simulated tropical cyclone structure and intensity to horizontal resolution. Mon. Wea. Rev., 138, 688-704, https://doi.org/10.1175/2009MWR2976.1.

Gray, M. W., 1968: Global view of the origin of tropical disturbances and storms. Mon. Wea. Rev., 96, 669-700, https://doi.org/ 10.1175/1520-0493(1968)096<0669:GVOTOO>2.0.CO;2.
Guimond, S. R., G. M. Hetmsfield, and F. J. Turk, 2010: Multiscale observations of Hurricane Dennis (2005): The effects of hot towers on rapid intensification. J. Atmos. Sci., 67, 633-654, https://doi.org/10.1175/2009JAS3119.1.

Hendricks, E. A., M. S. Peng, B. Fu, and T. Li, 2010: Quantifying environmental control on tropical cyclone intensity change. Mon. Wea. Rev., 138, 3243-3271, https://doi.org/10.1175/ 2010MWR3185.1.

Heymsfield, G. M., J. B. Halverson, J. Simpson, L. Tian, and T. P. Bui, 2001: ER-2 Doppler radar investigations of the eyewall of Hurricane Bonnie during the Convection and Moisture Experiment-3. J. Appl. Meteor., 40, 1310-1330, https://doi.org/ 10.1175/1520-0450(2001)040<1310:EDRIOT > 2.0.CO;2.

Holland, G. J., 1997: The maximum potential intensity of tropical cyclones. J. Atmos. Sci., 54, 2519-2541, https://doi.org/10.1175/ 1520-0469(1997)054<2519:TMPIOT>2.0.CO;2.

Holliday, C. R., and A. H. Thompson, 1979: Climatological characteristics of the rapidly intensifying typhoons. Mon. Wea. Rev., 107, 1022-1034, https://doi.org/10.1175/1520-0493(1979)107<1022: CCORIT $>2.0 . \mathrm{CO} ; 2$.

Hong, S.-Y., and J.-O. J. Lim, 2006: The WRF single-moment 6-class microphysics scheme (WSM6). J. Korean Meteor. Soc, 42, 129-151.

_, Y. Noh, and J. Dudhia, 2006: A new vertical diffusion package with an explicit treatment of entrainment processes. Mon. Wea. Rev., 134, 2318-2341, https://doi.org/10.1175/ MWR3199.1.

Houze, R. A., Jr., S. S. Chen, B. F. Smull, W.-C. Lee, and M. M. Bell, 2007: Hurricane intensity and eyewall replacement. Science, 315, 1235-1239, https://doi.org/10.1126/science.1135650.

Janjić, Z. I., 1994: The step-mountain eta coordinate model: Further developments of the convection, viscous sublayer, and turbulence closure schemes. Mon. Wea. Rev., 122, 927-945, https:// doi.org/10.1175/1520-0493(1994)122<0927:TSMECM>2.0.CO;2.

Kaplan, J., and M. DeMaria, 2003: Larger-scale characteristics of rapidly intensifying tropical cyclones in the North Atlantic basin. Wea. Forecasting, 18, 1093-1108, https://doi.org/10.1175/ 1520-0434(2003)018<1093:LCORIT > 2.0.CO;2.

_ , and Coauthors, 2015: Evaluating environmental impacts on tropical cyclone rapid intensification predictability utilizing statistical models. Wea. Forecasting, 30, 1374-1396, https://doi.org/ 10.1175/WAF-D-15-0032.1.

Kieu, C. Q., 2012: An investigation into the contraction of the hurricane radius of maximum wind. Meteor. Atmos. Phys., 115, 47-56, https://doi.org/10.1007/s00703-011-0171-7.

— , V. Tallapragada, D.-L. Zhang, and Z. Moon, 2016: On the development of double warm-core structures in intense tropical cyclones. J. Atmos. Sci., 73, 4487-4506, https://doi.org/ 10.1175/JAS-D-16-0015.1.

Kimball, S. K., and F. C. Dougherty, 2006: The sensitivity of idealized hurricane structure and development to the distribution of vertical levels in MM5. Mon. Wea. Rev., 134, 1987-2008, https://doi.org/10.1175/MWR3171.1.

Kimberlain, T. B., E. S. Blake, and J. P. Cangialosi, 2016: Hurricane Patricia. National Hurricane Center Tropical Cyclone Rep. EP202015, 32 pp., https://www.nhc.noaa.gov/data/tcr/EP202015_ Patricia.pdf.

Li, X., and Z. Pu, 2008: Sensitivity of numerical simulation of early rapid intensification of Hurricane Emily (2005) to cloud microphysical and planetary boundary layer parameterization. Mon. Wea. Rev., 136, 4819-4838, https://doi.org/10.1175/2008MWR2366.1.

Lim, K. S. S., and S. Y. Hong, 2010: Development of an effective double-moment cloud microphysics scheme with prognostic 
cloud condensation nuclei $(\mathrm{CCN})$ for weather and climate models. Mon. Wea. Rev., 138, 1587-1612, https://doi.org/ 10.1175/2009MWR2968.1.

Lin, Y.-L., R. D. Farley, and H. D. Orville, 1983: Bulk parameterization of the snow field in a cloud model. J. Climate Appl. Meteor., 22, 1065-1092, https://doi.org/10.1175/15200450(1983)022<1065:BPOTSF $>2.0$. CO;2.

Liu, Y., D.-L. Zhang, and M. K. Yau, 1997: A multiscale numerical study of Hurricane Andrew (1992). Part I: Explicit simulation and verification. Mon. Wea. Rev., 125, 3073-3093, https://doi.org/ 10.1175/1520-0493(1997)125<3073:AMNSOH > 2.0.CO;2.

,$- \ldots$, and — 1999: A multiscale numerical study of Hurricane Andrew (1992). Part II: Kinematics and inner-core structures. Mon. Wea. Rev., 127, 2597-2616, https://doi.org/ 10.1175/1520-0493(1999)127<2597:AMNSOH > 2.0.CO;2.

Marks, F. D., and Coauthors, 1998: Landfalling tropical cyclones: Forecast problems and associated research opportunities. Bull. Amer. Meteor. Soc., 79, 305-323, https://doi.org/10.1175/ 1520-0477(1998)079<0285:QPFROT>2.0.CO;2.

McFarquhar, G. M., H. Zhang, G. Heymsfield, J. B. Halverson, R. Hood, J. Dudhia, and F. Marks Jr., 2006: Factors affecting the evolution of Hurricane Erin (2001) and the distributions of hydrometeors: Role of microphysical processes. J. Atmos. Sci., 63, 127-150, https://doi.org/10.1175/JAS3590.1.

Michaels, P. J., P. C. Knappenberger, and R. E. Davis, 2006: Seasurface temperatures and tropical cyclones in the Atlantic basin. Geophys. Res. Lett., 33, L09708, https://doi.org/10.1029/ 2006 GL026268.

Miller, W., H. Chen, and D.-L. Zhang, 2015: On the rapid intensification of Hurricane Wilma (2005). Part III: Effects of latent heat of fusion. J. Atmos. Sci., 72, 3829-3849, https://doi.org/ 10.1175/JAS-D-14-0386.1.

Mlawer, E. J., S. J. Taubman, P. D. Brown, M. J. Iacono, and S. A. Clough, 1997: Radiative transfer for inhomogeneous atmosphere: RRTM, a validated correlated-k model for the longwave. J. Geophys. Res., 102, 16663-16682, https://doi.org/ 10.1029/97JD00237.

Morrison, H., G. Thompson, and V. Tatarskii, 2009: Impact of cloud microphysics on the development of trailing stratiform precipitation in a simulated squall line: Comparison of oneand two-moment schemes. Mon. Wea. Rev., 137, 991-1007, https://doi.org/10.1175/2008MWR2556.1.

Pattnaik, S., and T. N. Krishnamurti, 2007: Impact of cloud microphysical process on hurricane intensity. Part 2: Sensitivity experiments. Meteor. Atmos. Phys., 97, 127-147, https://doi.org/ 10.1007/s00703-006-0248-x.

Penny, A. B., P. A. Harr, and J. D. Doyle, 2016: Sensitivity to the representation of microphysical processes in numerical simulations during tropical storm formation. Mon. Wea. Rev., 144, 3611-3630, https://doi.org/10.1175/MWR-D-15-0259.1.

Qin, N., D.-L. Zhang, and Y. Li, 2016: A statistical analysis of steady eyewall sizes associated with rapidly intensifying hurricanes. Wea. Forecasting, 31, 737-742, https://doi.org/10.1175/WAF-D-16-0016.1.

Rappaport, E. N., and Coauthors, 2009: Advances and challenges at the National Hurricane Center. Wea. Forecasting, 24, 395 419, https://doi.org/10.1175/2008WAF2222128.1.

Rodgers, E. B., W. S. Olson, V. M. Karyampudi, and H. F. Pierce, 1998: Satellite-derived latent heating distribution and environmental influences in Hurricane Opal (1995). Mon. Wea. Rev., 126, 1229-1247, https://doi.org/10.1175/15200493(1998)126<1229:SDLHDA > 2.0.CO;2.

Rogers, R., P. D. Reasor, and S. Lorsolo, 2013: Airborne Doppler observations of the inner-core structural differences between intensifying and steady-state tropical cyclones. Mon. Wea. Rev., 141, 2970-2991, https://doi.org/10.1175/MWR-D-1200357.1.

— The extraordinary intensification of Hurricane Patricia (2015). Bull. Amer. Meteor. Soc., 98, 2091-2112, https://doi.org/ 10.1175/BAMS-D-16-0039.1.

Schubert, W. V., and J. J. Hack, 1982: Inertial stability and tropical cyclone development. J. Atmos. Sci., 39, 1687-1697, https://doi.org/ 10.1175/1520-0469(1982)039<1687:ISATCD>2.0.CO;2.

Skamarock, W. C., and Coauthors, 2008: A description of the Advanced Research WRF version 3. NCAR Tech. Note NCAR/TN-475+STR, 113 pp., http://dx.doi.org/10.5065/ D68S4MVH.

Steranka, J., E. B. Rodgers, and R. C. Gentry, 1986: The relationship between satellite-measured convective bursts and tropical cyclone intensification. Mon. Wea. Rev., 114, 1539-1546, https:// doi.org/10.1175/1520-0493(1986)114<1539:TRBSMC > 2.0.CO;2.

Stern, D. P., J. L. Vigh, D. S. Nolan, and F. Zhang, 2015: Revisiting the relationship between eyewall contraction and intensification. J. Atmos. Sci., 72, 1283-1306, https://doi.org/10.1175/JAS-D-140261.1.

Susca-Lopata, G., J. Zawislak, E. J. Zipser, and R. F. Rogers, 2015: The role of observed environmental conditions and precipitation evolution in the rapid intensification of Hurricane Earl (2010). Mon. Wea. Rev., 143, 2207-2223, https://doi.org/ 10.1175/MWR-D-14-00283.1.

Tallapragada, V., and C. Q. Kieu, 2014: Real-time forecasts of typhoon rapid intensification in the north western Pacific basin with the NCEP operational HWRF model. Trop. Cyclone Res. Rev., 3, 63-77.

_ Forecasting (HWRF) Model: 2014 scientific documentation. NCAR Development Testbed Center Rep. HWRF v3.6a, 105 pp., https://dtcenter.org/HurrWRF/users/docs/scientific_documents/ HWRFv3.6a_ScientificDoc.pdf.

Tao, W.-K., J. Simpson, and M. McCumber, 1989: An ice-water saturation adjustment. Mon. Wea. Rev., 117, 231-235, https:// doi.org/10.1175/1520-0493(1989)117<0231:AIWSA>2.0.CO;2.

, J. J. Shi, S. S. Chen, S. Lang, P.-L. Lin, S.-Y. Hong, C. PetersLidard, and A. Hou, 2011: The impact of microphysical schemes on hurricane intensity and track. Asia-Pac. J. Atmos. Sci., 47, 1-16, https://doi.org/10.1007/s13143-011-1001-z.

Thompson, G., P. R. Field, R. M. Rasmussen, and W. D. Hall, 2008: Explicit forecasts of winter precipitation using an improved bulk microphysics scheme. Part II: Implementation of a new snow parameterization. Mon. Wea. Rev., 136, 5095-5115, https:// doi.org/10.1175/2008MWR2387.1.

Wang, H., and Y. Wang, 2014: A numerical study of Typhoon Megi (2010). Part I: Rapid intensification. Mon. Wea. Rev., 142, 29-48, https://doi.org/10.1175/MWR-D-13-00070.1.

- — - and H.-M. Xu, 2013: Improving simulation of a tropical cyclone using dynamical initialization and largescale spectral nudging: A case study of Typhoon Megi (2010). Acta Meteor. Sin., 27, 455-475, https://doi.org/10.1007/s13351-013-0418-y.

Wang, Y., 2009: How do outer spiral rainbands affect tropical cyclone structure and intensity? J. Atmos. Sci., 66, 1250-1273, https://doi.org/10.1175/2008JAS2737.1.

Willoughby, H. E., 1990: Gradient balance in tropical cyclones. J. Atmos. Sci., 47, 265-274, https://doi.org/10.1175/15200469(1990)047<0265:GBITC>2.0.CO;2.

, J. A. Clos, and M. G. Shoreibah, 1982: Concentric eye walls, secondary wind maxima, and the evolution of the hurricane 
vortex. J. Atmos. Sci., 39, 395-411, https://doi.org/10.1175/ 1520-0469(1982)039<0395:CEWSWM >2.0.CO;2.

$\mathrm{Xu}$, J., and Y. Wang, 2015: A statistical analysis on the development of tropical cyclone intensification rate on the storm intensity and size in the North Atlantic. Wea. Forecasting, 30, 692-701, https://doi.org/10.1175/WAF-D-14-00141.1.

Yau, M. K., Y. Liu, D.-L. Zhang, and Y. Chen, 2004: A multiscale numerical study of Hurricane Andrew (1992). Part VI: Smallscale inner-core structures and wind streaks. Mon. Wea. Rev., 132, 1410-1433, https://doi.org/10.1175/1520-0493(2004)132<1410: $\mathrm{AMNSOH}>2.0 . \mathrm{CO} ; 2$.

Zhang, D.-L., and E. Altshuler, 1999: The effects of dissipative heating on hurricane intensity. Mon. Wea. Rev., 127, 3032-3038, https://doi.org/10.1175/1520-0493(1999)127<3032: TEODHO $>2.0 . \mathrm{CO} ; 2$.

, and X. Wang, 2003: Dependence of hurricane intensity and structures on vertical resolution and time-step size. $A d v$. Atmos. Sci., 20, 711-725, https://doi.org/10.1007/BF02915397.

, and H. Chen, 2012: Importance of the upper-level warm core in the rapid intensification of a tropical cyclone. Geophys. Res. Lett., 39, L02806, https://doi.org/10.1029/2011GL050578.

, Y. Liu, and M. K. Yau, 2001: A multiscale numerical study of Hurricane Andrew (1992). Part IV: Unbalanced flows.
Mon. Wea. Rev., 129, 92-107, https://doi.org/10.1175/15200493(2001)129<0092:AMNSOH>2.0.CO;2.

— L. Zhu, X. Zhang, and V. Tallapragada, 2015: Sensitivity of idealized hurricane intensity and structures under varying background flows and initial vortex intensities to different vertical resolutions in HWRF. Mon. Wea. Rev., 143, 914-932, https://doi.org/10.1175/MWR-D-14-00102.1.

Zheng, Y., K. Alapaty, J. Herwehe, A. D. Del Genio, and D. Niyogi, 2016: Improving high-resolution weather forecasts using the Weather Research and Forecasting (WRF) Model with an updated Kain-Fritsch scheme. Mon. Wea. Rev., 144, 833-860, https://doi.org/10.1175/MWR-D-15-0005.1.

Zhu, T., and D.-L. Zhang, 2006: Numerical simulation of Hurricane Bonnie (1998). Part II: Sensitivity to cloud microphysical processes. J. Atmos. Sci., 63, 109-126, https://doi.org/10.1175/JAS3599.1.

,-- , and F. Weng, 2004: Numerical simulation of Hurricane Bonnie (1998). Part I: Model verification and evolution of the eyewall. Mon. Wea. Rev., 132, 225-241, https://doi.org/ 10.1175/1520-0493(2004)132<0225:NSOHBP $>2.0$.CO;2.

Zhu, Z., and P. Zhu, 2014: The role of outer rainband convection in governing the eyewall replacement cycle in numerical simulations of tropical cyclones. J. Geophys. Res. Atmos., 119, 8049-8072, https://doi.org/10.1002/2014JD021899. 